\title{
RESEARCH
}

Open Access

\section{Elimination of intravascular thrombi prevents early mortality and reduces gliosis in hyper-inflammatory experimental cerebral malaria}

Kyle D. Wilson ${ }^{1}$, Lorenzo F. Ochoa², Olivia D. Solomon², Rahul Pal², Sandra M. Cardona ${ }^{3}$, Victor H. Carpio ${ }^{1}$, Philip H. Keiser ${ }^{5}$, Astrid E. Cardona ${ }^{3}$, Gracie Vargas ${ }^{2,4,6}$ and Robin Stephens ${ }^{1,5,6^{*}}$ (D)

\begin{abstract}
Background: Cerebral malaria (CM) is the most lethal outcome of Plasmodium infection. There are clear correlations between expression of inflammatory cytokines, severe coagulopathies, and mortality in human CM. However, the mechanisms intertwining the coagulation and inflammation pathways, and their roles in $\mathrm{CM}$, are only beginning to be understood. In mice with T cells deficient in the regulatory cytokine IL-10 (IL-10 KO), infection with Plasmodium chabaudi leads to a hyper-inflammatory response and lethal outcome that can be prevented by anti-TNF treatment. However, inflammatory $T$ cells are adherent within the vasculature and not present in the brain parenchyma, suggesting a novel form of cerebral inflammation. We have previously documented behavioral dysfunction and microglial activation in infected IL-10 KO animals suggestive of neurological involvement driven by inflammation. In order to understand the relationship of intravascular inflammation to parenchymal dysfunction, we studied the congestion of vessels with leukocytes and fibrin(ogen) and the relationship of glial cell activation to congested vessels in the brains of $P$. chabaudi-infected IL-10 KO mice.
\end{abstract}

Methods: Using immunofluorescence microscopy, we describe severe thrombotic congestion in these animals. We stained for immune cell surface markers (CD45, CD11b, CD4), fibrin(ogen), microglia (Iba-1), and astrocytes (GFAP) in the brain at the peak of behavioral symptoms. Finally, we investigated the roles of inflammatory cytokine tumor necrosis factor (TNF) and coagulation on the pathology observed using neutralizing antibodies and low-molecular weight heparin to inhibit both inflammation and coagulation, respectively.

Results: Many blood vessels in the brain were congested with thrombi containing adherent leukocytes, including CD4 T cells and monocytes. Despite containment of the pathogen and leukocytes within the vasculature, activated microglia and astrocytes were prevalent in the parenchyma, particularly clustered near vessels with thrombi. Neutralization of TNF, or the coagulation cascade, significantly reduced both thrombus formation and gliosis in $P$. chabaudi-infected IL-10 KO mice.

(Continued on next page)

\footnotetext{
* Correspondence: rostephe@utmb.edu

${ }^{1}$ Department of Microbiology and Immunology, University of Texas Medical Branch, 301 University Boulevard, Galveston, TX 77555, USA

${ }^{5}$ Department of Internal Medicine, Division of Infectious Diseases, University of Texas Medical Branch, 301 University Boulevard, Galveston, TX 77555-0435, USA

Full list of author information is available at the end of the article
}

(c) The Author(s). 2018 Open Access This article is distributed under the terms of the Creative Commons Attribution 4.0 International License (http://creativecommons.org/licenses/by/4.0/), which permits unrestricted use, distribution, and reproduction in any medium, provided you give appropriate credit to the original author(s) and the source, provide a link to the Creative Commons license, and indicate if changes were made. The Creative Commons Public Domain Dedication waiver (http://creativecommons.org/publicdomain/zero/1.0/) applies to the data made available in this article, unless otherwise stated. 
(Continued from previous page)

Conclusions: These findings support the contribution of cytokines, coagulation, and leukocytes within the brain vasculature to neuropathology in malaria infection. Strikingly, localization of inflammatory leukocytes within intravascular clots suggests a mechanism for interaction between the two cascades by which cytokines drive local inflammation without considerable cellular infiltration into the brain parenchyma.

Keywords: Malaria, Brain, Inflammation, Neuropathology, Vascular congestion, Monocyte, Astrocyte, Microglia, Immunofluorescence, Confocal microscopy,

\section{Background}

With 212 million new cases and 429,000 estimated deaths in 2015, malaria remains one of the most economically impactful infectious diseases worldwide [1]. A small percentage of Plasmodium falciparum infections results in severe malarial disease. However, a significant proportion of severe malaria infections includes cerebral malaria (CM), which is a leading cause of death in sub-Saharan African children and represents a major burden worldwide [2]. CM accounts for an estimated 500,000 cases per year and correlates with high parasitemic burden, severe inflammation, and cerebral edema [2]. Furthermore, about $20 \%$ of patients with CM die despite timely treatment [3], and neurological sequelae in survivors is common [4]. Several host genetic factors have been implicated in pathology. For example, mutations in the promoters of the inflammatory cytokine tumor necrosis factor (TNF), which drives the anti-malaria response of phagocytes, and the regulatory cytokine IL-10, which protects the host from excessive immunopathology, have been correlated with severe disease in both mice and humans [5-10]. However, inflammatory cytokines also allow parasite sequestration and leukocyte adhesion by upregulating adhesion molecules on the vascular endothelium [11-13].

The role of inflammatory cytokines increased by the absence of IL-10 has been studied extensively in the Plasmodium chabaudi mouse model of severe malaria [14]. P. chabaudi is a rodent parasite that leads to mild malaria in C57BL/6 (WT) mice. However, in IL-10-deficient (IL-10 KO) mice, $P$. chabaudi infection leads to hyper-inflammation and death. The syndrome includes increased levels of the pro-inflammatory cytokines TNF and IFN- $\gamma$ [14] and lethal disease characterized by cerebral pathology including cerebral edema and hemorrhage [15]. In addition, we have recently demonstrated pathological behavioral phenotypes indicative of neurological and cognitive dysfunction in this model [16]. Strikingly, there is no significant parasite sequestration in the brains of these mice. While a few parasites have been detected in the brain vasculature via electron microscopy [17], a more recent examination of the brain using highly sensitive luminescence technology to detect luciferin-expressing $P$. chabaudi parasites did not show significant enrichment [18]. The P. chabaudi life cycle is synchronous. Mature schizonts disappear from the circulation almost completely and are found sequestered primarily in the liver and lungs of mice in a partially ICAM1-dependent manner [19]. Interestingly, pathological damage within each organ in $P$. chabaudi does not correspond to the degree of organ-specific sequestration of the parasite [18]. Sequestration is a hallmark of autopsy in fatal P. falciparum-induced CM cases [20, 21 ], and specific parasite variants are associated with severe malaria [22-25]; however, it is challenging to definitively prove that parasite sequestration in the brain is causal to CM.

Activated immune cells and pro-inflammatory cytokines are also strongly implicated in the mortality in human disease $[26,27]$. A low ratio of IL-10 to TNF in patients predicts more severe malaria, as do mutations in the IL-10 and TNF genes [28, 29]. Mouse models show that this is because IL-10 is required to protect animals from lethal pathology, as it regulates the pro-inflammatory cytokines IL-12 and TNF [30], which drive as yet poorly defined neuroimmunopathology. IL-10 KO mice lacking IFN- $\gamma$ receptor signaling are also rescued from mortality, even though they exhibit higher levels of parasitemia [31]. IL-10 is primarily made by $\mathrm{CD}^{+}{ }^{+}$IFN $-\gamma^{+}$effector T cells (Teff) in P. chabaudi infection, not Tregs, and is downstream of IL-27 [32, 33], and we have shown that CD4 Teff are found solely within the cerebral vasculature, not in the brain parenchyma [16].

While there are studies of host genetics and those correlating systemic inflammatory cytokines with poor outcomes in severe malaria $[26,27]$, no significant inflammatory infiltrate within the brain parenchyma has been documented in human or mouse studies of the disease [20, 21, 34-40]. As a result, the contribution of activated peripheral leukocytes to brain pathology has been poorly appreciated. Interestingly, despite the lack of infiltrating inflammatory cells in the brain parenchyma, we have documented increased microglial activation in this model [16]. This is intriguing because glia are found behind the multi-layered blood-brain barrier (BBB), while activated peripheral immune cells are within the vasculature [16]. This prompted the question 
of how the inflammatory cells within the vasculature could amplify cytokine production in the absence of a lymphoid structure, such as that developing in neuroimmunopathologies with parenchymal infiltrates.

Congestion of the brain and retinal vasculature has been documented in human cerebral malaria and is associated with poor prognoses in human cases of CM [41, 42]. Several factors are likely to contribute to congestion in human patients: parasite sequestration, leukocyte adhesion, and coagulation defects. Parasite-infected erythrocytes can both bind to the vascular endothelium, leading to activation and vascular dysfunction, and activate the coagulation cascade $[43,44]$. Coagulation defects are also seen in both murine experimental cerebral malaria and in human cerebral malaria [45-47] and can be promoted by the parasite itself [45]. Vascular thrombi were observed in CM2 patients in Malawi, who are documented to have both sequestration and cerebral hemorrhages [20]. This supports the finding that disseminated intravascular coagulation (DIC) was observed in $19 \%$ of CM patients and correlated with poor outcomes [48]. However, the role of coagulation in neuropathology is obscured by contradictory outcomes in studies of the effect of the anticoagulant, heparin $[49,50]$. In clinical trials, heparin significantly reduced death in a clinical trial in children with CM in Indonesia (from 13/17 to $2 / 16,[50])$ and reduced patient's coma and hospitalization time [49]. However, it is not currently recommended for treatment due to the potential of systemic hemorrhagic side effects of this older drug, suggested by work in non-human primates [51] and case studies of malarious soldiers in Asia with pulmonary involvement [52], though not seen in clinical trials. The presence of monocytes and $\mathrm{T}$ cells in the brain vasculature [20], but not in the brain parenchyma [34], is also documented. This has often been interpreted as a "lack of inflammation," despite strong evidence, both genetic and serological, that cytokines play a critical role in killing parasite and inducing pathology [53].

In an attempt to understand the role of adherent intravascular leukocytes and coagulation in promoting neuronal malfunction, we investigated the contents of congested vessels and their effects on the brain parenchyma, as measured by gliosis. Furthermore, we tested the role of coagulation in pathology by studying the effect of anticoagulants on mortality and histological features of inflammation-driven neuropathology in $P$. chabaudi infection of IL-10 KO mice. We found that thrombi were prevalent throughout the brain and coincide with localization of adherent leukocytes. In addition, areas of coagulation and leukocytes co-localized with parenchymal gliosis. We also found a striking reduction of mortality and a significantly recovered parenchymal histology on elimination of coagulation suggesting a pathological role for thrombi in this model. These observations suggest an important role of coagulation in vascular congestion in CM and also implicate a novel mechanism of inflammation-induced neuropathology possibly initiated by leukocytes contained within the vasculature. These findings may be relevant because the inflammation-driven neuropathology in this model shares many features with human cerebral malaria, including intravascular leukocytes and thrombi, systemic hyper-inflammation, edema, and death.

\section{Methods \\ Mice}

C57BL/6J (WT) and B6.129P2-Il10 ${ }^{\mathrm{tm} 1 \mathrm{Cgn}} / \mathrm{J}$ (IL-10 KO) mice (Jackson Laboratory, Bar Harbor, ME) were bred in The University of Texas Medical Branch Animal Resource Center. Experimental mice were female and between 6 and 12 weeks of age at the time of infection. All animals were kept in a specific pathogen-free housing with ad libitum access to food and water. Animals were cared for according to the Guide for the Care and Use of Laboratory Animals under Institutional Animal Care and Use Committee-approved protocols. UTMB Animal Resource Center facilities operate in compliance with the USDA Animal Welfare Act, the Guide for the Care and Use of Laboratory Animals, under OLAW accreditation, and IACUC-approved protocols.

\section{Parasite and infection}

Frozen stocks of Plasmodium chabaudi chabaudi $(A S)$-infected RBCs (iRBCs) (Jean Langhorne, Francis Crick Institute, London, UK) kept at $-80{ }^{\circ} \mathrm{C}$ were thawed and injected intraperitoneally (i.p.) into WT mice. Parasitized blood from these animals was diluted in Krebs-Ringer bicarbonate buffer (Sigma-Aldrich, St. Louis, MO) and normal saline to deliver $10^{5}$ iRBCs i.p. in $200 \mu \mathrm{l}$ into experimental WT or IL-10 KO mice. Thin blood smears were collected at regular intervals to monitor for peripheral parasitemia by staining with Diff-Quik (Siemens Healthcare Diagnostics, Newark, DE) or Giemsa stain (Ricca Chemical Company, Arlington, TX) and counted on a light microscope.

\section{Animal body temperature and weight}

Internal body temperatures were assessed daily during infection using rounded stainless steel rectal probes and a BIO-TK8851 digital rodent model thermometer (Bioseb, Pinellas Park, FL). Probes were sanitized with CaviCide (Metrex Research Corp., Romulus, MI) between each use. Animal weights were measured using an OHAUS Scout Pro SP601 portable balance (OHAUS, Parsippany, NJ).

\section{Animal behavior evaluation}

Beginning on day 5 post-infection, daily assessments were performed on all animals using an abbreviated version of the modified SmithKline Beecham, Harwell, 
Imperial College, Royal London Hospital Phenotype Assessment (SHIRPA) protocol [54]. This brief behavioral assessment was developed based on the full assessment in a previous study [16]. Higher scores were awarded for measures showing higher functional ability. The procedures were carried out in an open testing environment away from the home cage and took approximately $5 \mathrm{~min}$ per animal.

The abbreviated SHIRPA used involves a selection of nine semi-quantitative tests for general health and sensory function, baseline behaviors, and neurological reflexes. We observed undisturbed behavior with the mouse placed in an inverted beaker on top of a metal grid suspended above the home cage for $3 \mathrm{~min}$, during which body position and spontaneous activity were assessed. Body position scores ranged from 0 (completely flat) to 5 (repeated vertical leaping). Spontaneous activity scores ranged from 0 (none) to 4 (rapid/dart movement). At the end of the observation period, palpebral closure, which was scored from 0 (eyes closed) to 2 (eyes wide open), and qualitative grip strength, scored from 0 (none) to 4 (unusually strong), are tested by applying a gentle horizontal force on the animal's tail as it grips the metal grid. The animal is then placed in an open arena in which several behaviors are measured. Gait is observed as the animal traverses the arena and is scored from 0 (incapacity) to 3 (normal). During movement, tail elevation is scored, ranging from 0 (dragging) to 2 (elevated). Touch escape measures the reaction to a finger stroke and is scored from 0 (no response) to 3 (escape response to approach). Palpation of the animal's sternum determines heart rate: 0 (slow) to 2 (fast), and finally, righting reflex is scored by releasing the animal from an upside-down position near the surface and observing the responding effort to upright itself, scored from 0 (fails to right) to 3 (lands on feet). The expected score of a healthy, uninfected IL-10 KO or WT mouse is 22. A score of 15 was identified as the humane endpoint based on the finding that any female animal that drops below that score by day 9 will succumb to infection (see Additional file 1: Figure S1).

\section{Histochemistry}

Immunofluorescence of cryosections was examined after $48 \mathrm{~h}$ of post-fixation of mouse brains in 4\% PFA and $72 \mathrm{~h}$ of cryoprotection in 30\% sucrose. Fixed frozen sagittal sections $(30 \mu \mathrm{m})$ were made using Tissue Plus ${ }^{\ominus}$ Optimal Cutting Temperature Compound (Fisher Healthcare, Houston, TX) and mounted on glass slides with Fluoromount mounting medium (Novus Biologicals, Littleton, $\mathrm{CO})$. Sections were incubated overnight at $4{ }^{\circ} \mathrm{C}$ with primary antibodies rabbit anti-fibrinogen (catalog no. A0080, Agilent Technologies, Carpinteria, CA), rat (clone 2.2B10, catalog no 13-0300, Thermo Fisher Scientific, Waltham,
MA), or rabbit (catalog no. Z0334, Agilent Technologies, Carpinteria, CA) anti-GFAP, mouse anti-CD11b biotin (clone M1/70, catalog no. 13-0112-85, eBioscience, San Diego, CA), and rat anti-CD45 biotin (clone 104, catalog no. 13-0454-85, eBioscience, Sand Diego, CA). Secondary antibodies used were goat anti-rat AlexaFluor-488 (catalog no. A11006, Thermo Fisher Scientific, Waltham, MA) and goat anti-rabbit AlexaFluor-568 (catalog no. A11011, Thermo Fisher Scientific, Waltham, MA). Streptavidin-FITC (catalog no. 11-4317-87, eBioscience, San Diego, CA) was used as a tertiary step for biotinylated antibodies. CellTrace Violet (catalog no. C34557, Thermo Fisher Scientific, Waltham, MA)-labeled CD4 T cells were adoptively transferred into IL-10 $\mathrm{KO}$ mice for later co-localization with brain vasculature after i.v. perfusion with DyLight488-labeled tomato lectin (catalog no. DL-1174, Vector Laboratories, Burlingame, CA). Images of immunohistochemistry (IHC) sections were taken with an Olympus IX 71 inverted brightfield microscope using a $\times$ 20 air objective, while the immunofluorescence images were taken with a confocal microscope (Olympus FV 1000) with the DAPI channel for nuclei, Alexa 488 channel for Iba1 tagged with Alexa 488, and Alexa 647 channel for CD 31 tagged with Alexa 647. IHC images of Iba1-stained sections were contrast-enhanced and segmented by threshold for microglia using ImageJ (NIH, Version 1.48u). These were used to create binary images. Individual microglia were identified using a semi-automatic algorithm employing the particle analysis function on image and average area per microglia; the microglia density and total immunoreactive area were calculated from the binary images. Area fraction of small processes is a ratio of immunoreactive area without microglia to total immunoreactive area which indicates the degree of ramification. Transformation index, and indicator of activation, was calculated as T-Index = $\left(\right.$ Perimeter $\left.^{2}\right) /(4 \pi \times$ Area) per microglia. To quantitatively describe the degree of ramification, we calculated the area fraction of small thin processes to total immunoreactive area. Ramification could be seen in IHC images as glia with long and thin processes that appeared segmented due to branching in and out of the tissue section plane. The astrocyte-thrombus association index was defined in which the ratio of $X_{\mathrm{i}}$ (the number of astrocytes contacting a thrombus divided by the total number of thrombi) was calculated, and values were normalized based on the following equation, $\left(X_{\mathrm{i}}-X_{\min }\right) /\left(X_{\max }-X_{\min }\right)$, where $X_{\min }=1.3$ (lower limit of astrocyte-thrombi interaction seen in uninfected IL-10 KO brains) and $X_{\max }=3.25(\sim 75 \%$ astrocyte/thrombi association) approximated the lower and upper limit of astrocytes interacting with thrombi based on our data.

\section{Cell and in vivo labeling}

Some infected IL-10 KO and WT animals were injected with $2 \times 10^{6} \mathrm{CTV}^{+} \mathrm{CD} 4 \mathrm{~T}$ cells $3.5 \mathrm{~h}$ before sacrifice 
(i.p.) and $40 \mu \mathrm{g}$ of DyLight488 labeled Lycopersicon esculentum (tomato) Lectin (catalog no. DL-1174, Vector Laboratories, Burlingame, CA) $20 \mathrm{~min}$ before sacrifice (i.v.). CellTrace Violet (catalog no. C34557, Thermo Fisher Scientific, Waltham, MA) labeling was performed as previously described [55].

\section{Anti-TNF antibody treatment}

Mice receiving anti-TNF antibody (clone XT3.11, Bio X Cell, West Lebanon, $\mathrm{NH}$ ) were treated with $0.2 \mu \mathrm{g} /$ day for 5 days starting on day 5 post-infection (days 5-9). Untreated mice received isotype rat IgG1 as a control.

\section{CLARITY and optical clearing}

Fixed brain sections (IL-10 KO and WT) were subjected to the passive CLARITY optical clearing method [56] for large-scale labeling and imaging. In brief, mice were anesthetized and perfused transcardially with a mixture of $4 \%(\mathrm{wt} / \mathrm{vol})$ PFA, 4\% (wt $/ \mathrm{vol}$ ) acrylamide, $0.05 \%(\mathrm{wt} /$ vol) bis-acrylamide, and $0.25 \%$ (wt/vol) VA044 (hydrogel solution) in PBS. Brains were extracted and incubated in hydrogel solution at $4{ }^{\circ} \mathrm{C}$ for 3 days. Solution temperature was then increased for $3 \mathrm{~h}$ to $37^{\circ} \mathrm{C}$ to initiate polymerization. Hydrogel-embedded brains were sectioned into 2-mm-thick sagittal sections and placed in clearing solution (sodium borate buffer, $200 \mathrm{mM}, \mathrm{pH}$ 8.5) containing $4 \%(\mathrm{wt} / \mathrm{vol}) \mathrm{SDS})$ for 3 weeks at $40{ }^{\circ} \mathrm{C}$ under gentle agitation. Samples were immunostained for GFAP to assess astrogliosis. After immunostaining, samples were optically cleared using increasing serial concentrations (10-100\%) of 2,2'-thiodiethanol (TDE) in Milli-Q water (EMD Millipore, Darmstadt, Germany) to achieve optimal refractive index matching with tissue.

\section{Microscopy}

Fixed cryosections $(30 \mu \mathrm{m}$ thickness, fluorescent or confocal microscopy) were imaged with a Nikon Eclipse 80i epifluorescence microscope and a Fluoview 1000MPE system configured with an upright BX61 microscope (Olympus, Center Valley, PA). Fixed, CLARITY-processed sections (2 mm thickness, two-photon confocal microscopy) were imaged using a Prairie Ultima IV (Prairie Technologies/Bruker, Middleton, WI) upright multiphoton microscope. For two-photon fluorescence microscopy, a $\times 100.3$ N.A. objective (UPLFL10X, Olympus) and a $\times$ 251.05 N.A. super-objective (XLSLPLN25XGMP, Olympus) were used for image collection. Illumination for excitation of fluorescence was provided by a femtosecond laser (Mai Tai, SpectraPhysics, Santa Clara, CA) tuned to $800 \mathrm{~nm}$. Fluorescence was collected using a two-photon standard M filter set including filters with bandwidth 604 $\pm 45 \mathrm{~nm}$, a filter with bandwidth $525 \pm 70 \mathrm{~nm}$, and dichroic mirror cutoff at $575 \mathrm{~nm}$. Samples were mounted on a $30-\mathrm{mm}$ cage plate (CP06, ThorLabs, Newton, NJ) between two \#1.5 cover glass. To visualize large regions of optically cleared brain tissue using two-photon microscopy, image stack mosaic and stitching were applied. Image stack stitching was done with a $10 \%$ overlap on a field of view of $2327.3 \times 237.3 \mu \mathrm{m}$ providing $232.73 \mu \mathrm{m}$ of co-registration in $X$ and $Y$ coordinates. Images were analyzed using ImageJ (FIII), Olympus Fluoview FV1000-ASW 2.0 Viewer (confocal), Imaris Image Analysis Software (confocal and two-photon microscopy; Bitplane USA, Concord, MA), and NIS Elements (confocal; Nikon Instruments, Melville, NY). Positive fibrinogen and elevated GFAP staining in each field was quantified by applying a signal intensity threshold and the percent area covered was calculated via the outlined areas of positive staining that met the signal intensity threshold per field of view. The percentage of total area included was calculated using ImageJ software (FIJI, NIH).

\section{Ammonia assay}

Tissue and serum ammonia was quantified using a commercial colorimetric ammonia assay kit (ab83360, Abcam, Cambridge, MA). Briefly, brain and liver samples were collected from infected IL-10 KO and WT mice at the peak of behavioral symptoms, washed in cold PBS, resuspended in $100 \mu \mathrm{l}$ assay buffer, and homogenized using a Dounce homogenizer to produce single-cell suspensions. After $2-5 \mathrm{~min}$ of centrifugation at $4{ }^{\circ} \mathrm{C}$, cells were counted via hemocytometer and seeded into a 96-well plate to provide $1-5 \times 10^{4}$ cells/ well. Serum samples were counted and seeded directly into plates without processing $(5-10 \mu \mathrm{l} /$ well). The colorimetric assay was conducted using OxiRed probe. Color change was recorded at OD $570 \mathrm{~nm}$ using a spectrophotometer microplate reader and compared to an ammonium chloride standard curve (detects $0-10 \mathrm{nmol} /$ well) after $60 \mathrm{~min}$ of incubation at $37^{\circ} \mathrm{C}$.

\section{Statistics}

Where indicated, groups were compared by $t$ test (2 groups) or one-way ANOVA (3 or more groups), followed by post hoc Bonferroni method or Tukey's test to identify significance between individual groups. Each point represents the average value per animal after analysis of 10 fields, unless otherwise specified. Statistical analysis was performed in Prism (GraphPad, La Jolla, CA), $" p \leq 0.05,{ }^{* * *} p \leq 0.01$, and ${ }^{* * * *} p \leq 0.001$. Error bars represent \pm SEM.

\section{Results}

Congestion of brain blood vessels with thrombi containing $\mathrm{CD}_{4} 5^{+}, \mathrm{CD}_{11} \mathrm{~b}^{+}$, and $\mathrm{CD} 4^{+}$leukocytes in $P$. chabaudi-infected IL-10 KO mice

To investigate vascular abnormalities in $P$. chabaudi-infected IL-10 KO mice, we examined sagittal sections of perfused and fixed brain tissue for evidence of vascular 
leakage as indicated by extravascular fibrinogen at the peak of infection (day 8 post-infection). Brains from infection-matched, disease-resistant WT mice were used as controls (Fig. 1a). In addition to the expected sites of perivascular fibrinogen (evidence of fibrinogen leakage), we also found foci of fibrin(ogen) staining within the vascular lumen of brain blood vessels in IL-10 KO mice. As we had performed transcardial perfusion prior to sacrifice, this data is suggestive of intravascular thrombi. Quantification of fibrin(ogen) staining in the IL-10 KO mice showed an increase in the area of the brain with bright fibrinogen immunoreactivity (percent area of Alexa Fluor $568^{+}$pixels, 10 fields/mouse) compared to infected WT, or uninfected, which were indistinguishable from each other (Fig. 1b). There was also a large increase in staining of fibrinogen in the livers of infected IL-10 KO compared to WT, which had some lighter staining as well that was not quantifiable over background levels in uninfected mice (Fig. 1c). This could potentially be due to an increase in fibrinogen production by the IL-10 $\mathrm{KO}$ mouse downstream of inflammation, as fibrinogen is an acute phase response protein [57]. However, while increased systemic production of fibrinogen is a risk factor for coagulation, it does not lead to clotting by itself [58]. However, an increase in liver fibrinogen production is not sufficient for accumulation of fibrin, which is triggered by the coagulation cascade $[57,58]$.

Studies of both human $\mathrm{CM}$ and murine experimental cerebral malaria (ECM) have documented congestion of the brain and retinal vasculature, but the role of thrombi in reduced blood flow is not clear. By imaging through $200 \mu \mathrm{m}$ of tissue, we found that both large and small vessels retain intravascular fibrin(ogen) (Fig. 2a), often to the point of complete occlusion of the vascular lumen (Fig. 2b), reminiscent of thrombosis. The coagulation cascade leads to cleavage of fibrinogen into fibrin during the formation of a clot [59]. The polyclonal antiserum used to detect fibrinogen here also detects fibrin and other degradation products of fibrinogen $[60,61]$. Therefore, we interpret this staining pattern to represent fibrin clots. The appearance of sherical gaps in fibrin staining led us to hypothesize that in addition to red blood cells and platelets, immune cells could be retained within the thrombi of congested vessels. In order to identify them, we stained IL-10 KO brains for the
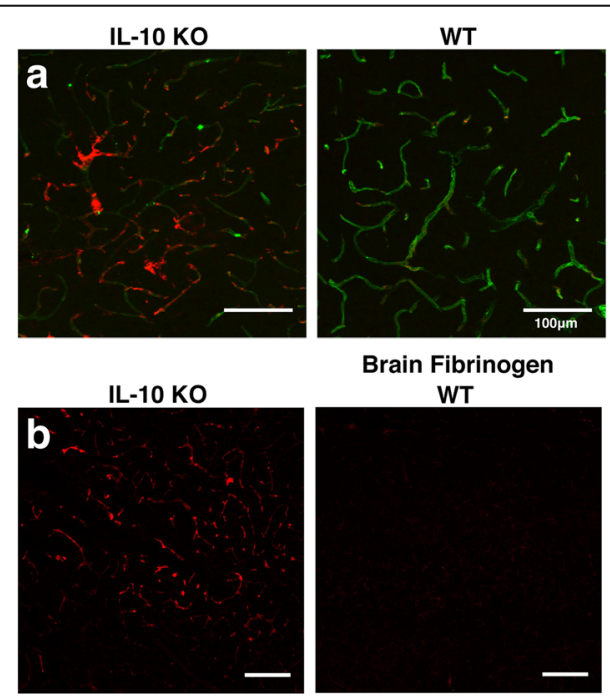

Brain Fibrinogen
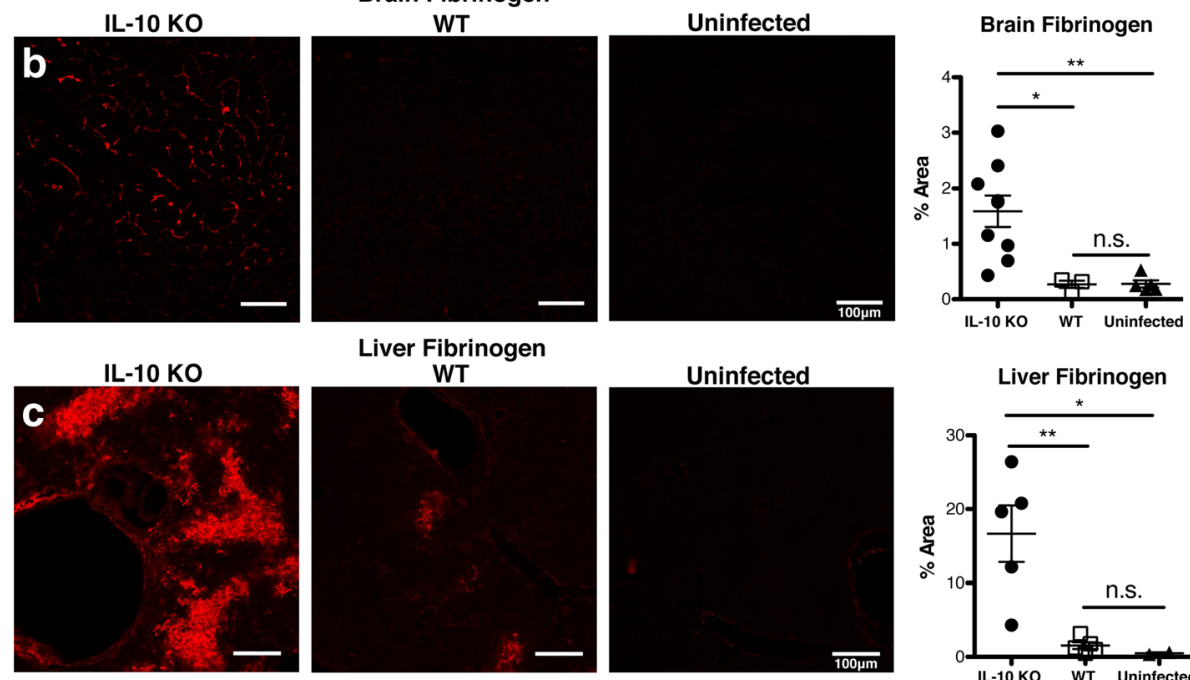

Liver Fibrinogen
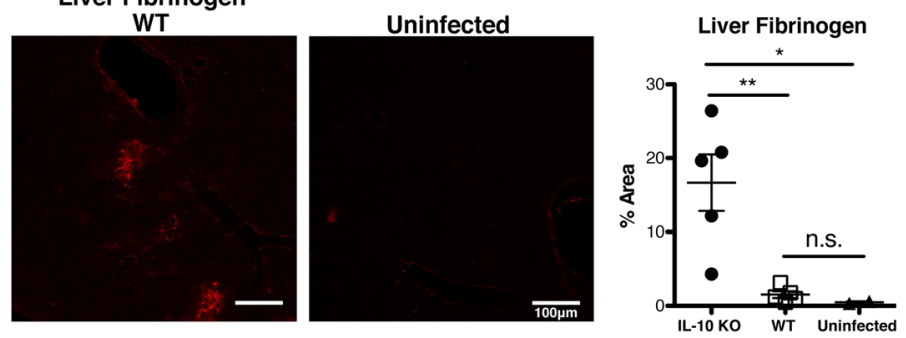

Fig. $1 \mathrm{lL}-10 \mathrm{KO}$ mice have residual fibrin deposition in and around brain vasculature and increased liver fibrinogen. a Confocal images $(\times 20)$ showing immunofluorescent staining of fixed, frozen brain sections $(30 \mu \mathrm{m})$ from $P$. chabaudi-infected IL-10 KO and WT mice (day 8 p.i., $n=4$ mice/group). Fibrin (red) and tomato lectin (green, vascular endothelium). b Fibrin (red) was quantified by surveying 10 fields per brain section ( $\times 10)$. Graph showing average percent area of fibrin-positive staining above threshold in each field. $\mathbf{c}$ Immunofluorescent staining $(\times 10)$ and quantitation of fibrinogen (red) in liver from infected IL-10 KO, WT, and uninfected controls ( $n=4$ mice/group). One-way ANOVA, followed by post hoc Bonferroni method, was used to determine statistical significance. ${ }^{*} p<0.05,{ }^{* *} p<0.01$. Scale bar represents $100 \mu \mathrm{m}$ 


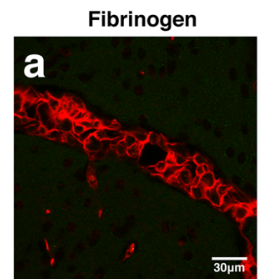

CD45

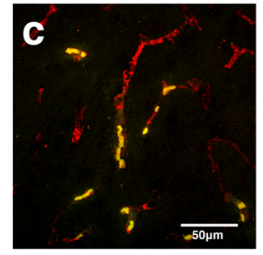

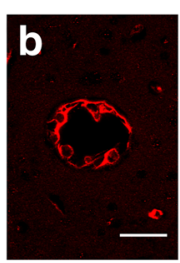

CD11b

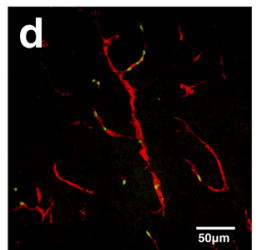

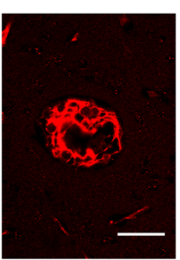
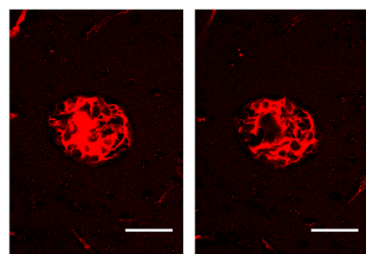

CD4

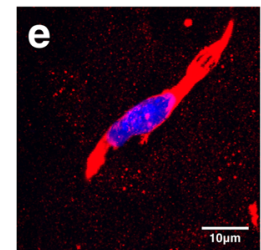

Fig. 2 Vascular congestion in IL-10 KO mice with malaria includes thrombi-containing monocytes and T cells. Immunofluorescent staining of fixed, frozen brain sections $(30 \mu \mathrm{m})$ from $P$. chabaudi-infected IL-10 KO mice (day 8 p.i., $n=4$ mice). a Confocal images $(\times 40)$ of IL-10 KO brain stained for fibrin (red). b Successive single-plane confocal images $(\times 40)$ of a 30- $\mu \mathrm{m}$ z-stack showing complete occlusion of a large vessel with residual fibrinogen (red). c Immunofluorescence staining of IL-10 KO brains showing fibrin staining of blood vessels (red) and leukocytes expressing CD45 (green, $\times 60$ ) and $\mathbf{d}$ CD11b (green, $\times 40$ ). e CTV ${ }^{+}$CD4 T cells (blue) from infected IL-10 KO mice were adoptively transferred into infection-matched IL-10 KO (day 7 p.i.) recipients $3.5 \mathrm{~h}$ before sacrifice. Frozen brain sections (day 7 p.i.) were stained for fibrin (red). Max intensity projection of a 30- $\mu \mathrm{m}$ z-stack ( $\times 240$ ) displayed from brain tissue of IL-10 KO mice co-stained with WT control samples ( $n=3-4$ mice per group). Scale bars represent $30 \mu \mathrm{m}(\mathbf{a}), 50 \mu \mathrm{m}(\mathbf{b}-\mathbf{d})$, or $10 \mu \mathrm{m}(\mathbf{d})$

pan-leukocyte marker, CD45 (Fig. 2c), and the monocyte marker, CD11b (Fig. 2d). Staining showed that many, but not all, $\mathrm{CD} 45^{+}$and $\mathrm{CD} 11 \mathrm{~b}^{+}$leukocytes are contained within areas of residual fibrinogen staining. We previously quantified $\mathrm{CD} 11 \mathrm{~b}^{+}$cells within the brains of $P$. chabaudi-infected IL-10 KO mice using flow cytometry. In that analysis, we showed that the $\mathrm{CD}_{11} \mathrm{~b}^{+}$cells were also $\mathrm{Ly} 6 \mathrm{C}^{+}$, indicating that they are inflammatory monocytes [16]. There was a large and significant increase in cerebral Ly6 $\mathrm{C}^{\text {hi }}$ inflammatory monocytes in IL-10 KO compared to that in infected WT mice, while a Ly6C ${ }^{\text {int }}$ population of resident macrophages was not increased.

We were also interested to see if $\mathrm{CD} 4 \mathrm{~T}$ cells, the primary producers of IL-10 in this infection, were also found localized with fibrin(ogen) in the vessels. Therefore, CD4 $\mathrm{T}$ cells (CellTrace Violet ${ }^{+}$) from IL-10 KO mice 7 days post-infection (p.i.) were adoptively transferred into infection-matched IL-10 KO recipients, which underwent transcardial perfusion and brain tissue collection $3.5 \mathrm{~h}$ later. Transferred CD4 T cells were indeed identified in the brain, and often within a fibrin (ogen) ${ }^{+}$clot (Fig. 2e). While the number of leukocytes is not large, activated leukocytes have the potential to promote activation of the neuroglial cells surrounding the vasculature, namely, astrocytes. Therefore, we next tested brain sections from infected IL-10 KO animals for astrogliosis.

Inflammatory cytokine TNF induces astrocyte activation in clusters near thrombotic cerebral vasculature in IL-10 KO mice with malaria

As astrocytes play an important role in maintaining the integrity of the $\mathrm{BBB}$, including in the context of experimental cerebral malaria [62], we analyzed the extent of astrocyte activation in IL-10 KO mice infected with $P$. chabaudi. In order to visualize extensive activation of astrocytes, we utilized CLARITY followed by optical clearing, a tissue processing technique which removes relatively opaque lipids, transforming thick sagittal brain sections $(2 \mathrm{~mm})$ to make them optically transparent. This process diminishes excess light scattering during image acquisition by confocal or two-photon microscopy, allowing for increased imaging depth beyond that possible in unprocessed tissue. The ability to obtain image stacks over the full $2 \mathrm{~mm}$ thickness combined with image stitching allowed for image acquisition of the entire thick sagittal section. Whole brain sections stained for glial fibrillary acidic protein (GFAP), which is upregulated on activated astrocytes, were imaged to determine the extent of astrocyte activation in susceptible IL-10 KO mice (Fig. 3a, c, e) and resistant WT animals (Fig. 3b, d, f). A higher GFAP signal was observed in multiple areas of the IL-10 KO brain compared to WT, including the hippocampus, thalamus, and caudate putamen, suggesting astrocyte activation via increased production of inflammatory cytokines (Fig. 3a, b). While GFAP is expressed on most astrocytes, even in uninfected animals, the level of expression is significantly lower than on activated astrocytes [63]. Interestingly, there was little GFAP signal in the cortex, a result that is consistent with findings in human CM autopsy [20]. For quantitation of astrogliosis, we focused our analysis on the hippocampal formation (Fig. 3c, d), as a representative region in which astrogliosis was evident. This region is amenable to being isolated from other regions by 


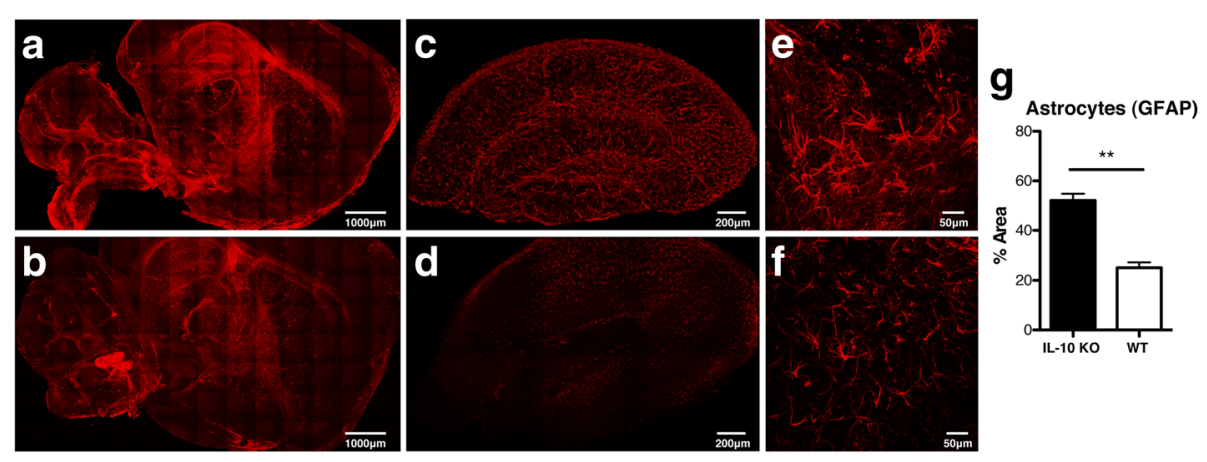

Fig. 3 Increased astrocyte activation in IL-10 KO mice with malaria. Mice were infected with P. chabaudi and sacrificed 8 days post-infection. Thick sagittal brain sections $(2 \mathrm{~mm}$ ) were CLARITY-processed, optically cleared, stained with GFAP (red), and imaged by two-photon confocal microscopy. a, c, e IL-10 KO and $\mathbf{b}, \mathbf{d}$, $\mathbf{f}$ WT brains from the peak of $P$. chabaudi infection (day 8 p.i., $n=5$ mice/group). a, $\mathbf{b}$ Single fields of the entire tissue section $(\times 10)$ stitched together. $\mathbf{c}$, $\mathbf{d}$ Hippocampus of the thick brain section is masked for increased resolution and quantitation in $\mathbf{c}$ IL-10 KO and $\mathbf{d}$ WT animals ( $n=3$ mice/group). e, $\mathbf{f}$ Representative high-resolution image $(\times 25)$ of astrocytes from the hippocampus showing the e IL-10 KO and $\mathbf{f}$ WT control brains. $\mathbf{g}$ Quantification of the percent area of astrocyte staining above threshold in the hippocampal formation of the $P$. chabaudi-infected IL-10 KO and WT brains. Number of fields for IL-10 KO $(n=15)$ and WT $(n=9)$. Scale bars represent $1 \mathrm{~mm}(\mathbf{a}, \mathbf{b}), 200 \mu \mathrm{m}$ $(\mathbf{c}, \mathbf{d})$, and $50 \mu \mathrm{m}(\mathbf{e}, \mathbf{f})$. Student's $t$ test was used to determine statistical significance. ${ }^{* *} p<0.01$

image processing due to its well-defined margin and thus allowed for comparison of GFAP ${ }^{\text {bright }}$ cells in the full volume of the hippocampal region in each section. As shown in high-resolution 3D micrographs (Fig. 3e, f), in addition to upregulation of GFAP, astrocytes in IL-10 KO mice showed distinct morphological changes, appearing hypertrophied and with more processes compared to infected WT. The GFAP ${ }^{\text {bright }}$ fraction of the hippocampal formation in infected IL-10 KO mice was significantly increased compared to WT mice (Fig. 3g). While elevated serum ammonia from potential liver damage can activate astrocytes [64], there was no significant difference in ammonia production between WT and IL-10 KO mice (Additional file 2: Figure S2). As inflammation, or vascular damage, can also lead to astrocyte activation, we next investigated whether vascular congestion and astrocyte activation occurred in close proximity.

To investigate the potential connection between vascular congestion and astrocyte activation, we performed immunofluorescent staining of peak-infected (day 7 p.i.) and uninfected IL-10 KO brains for fibrin(ogen) and astrocyte activation. In the hippocampal formation, we observed an increase in residual fibrin(ogen) staining in the infected IL-10 KO brains compared to WT (Fig. 4). Interestingly, the astrocytes showed an increase in GFAP staining and polarity and were more frequently found in contact with fibrin-containing vessels in infected IL-10 KO brains compared to infected WT and uninfected IL-10 KO controls (Additional file 3: Figure S3). However, it was noted that not all areas with residual fibrin staining were located near highly activated astrocytes. Uninfected mice showed neither residual fibrinogen deposition, nor an increase in GFAP immunoreactivity. Having established a link between microvascular congestion characterized by fibrin staining and astrocyte activation in this hyper-inflammatory response, we next sought to determine the role that inflammatory cytokines play in this process.

Immunopathology in IL-10 KO mice infected with $P$. chabaudi is generated by the hyper-inflammatory cytokine response generated in the absence of this regulatory cytokine primarily made by $\mathrm{T}$ cells [32]. Neutralizing TNF is known to improve survival and also improve all measures of symptomatic pathology, while Ifngr 1 deficiency in IL-10 KO mice improves survival [14, 31]. Importantly, neutralizing the other major regulatory cytokine, transforming growth factor- $\beta$, increases mortality of the IL-10 KO to $100 \%$, suggesting that the balance of inflammatory and regulatory cytokines in the immune response to malaria infection determines the lethality of $P$. chabaudi in IL-10 KO mice [14]. However, the role of TNF in brain pathology, including its behavioral results, has not yet been investigated in this model. As an indication of brain pathology, we used a semi-quantitative $P$. chabaudi-specific SHIRPA health assessment abbreviated from one we previously described [16]. We have now identified a smaller set of behavioral symptoms, described in the "Methods" section, that specifically change at the time that IL-10 KO mice begin to succumb to infection. The SHIRPA screen was highly predictive of outcome, as the SHIRPA scores of mice that died during infection were significantly lower than those of mice that survived (Additional file 1: Figure S1). In addition, we were able to use the abbreviated SHIRPA to identify animals predicted to succumb to hyper-inflammatory experimental cerebral malarial disease. Any $P$. chabaudi-infected IL-10 KO mouse that scored below 17, out of a maximum of 22 , on the 


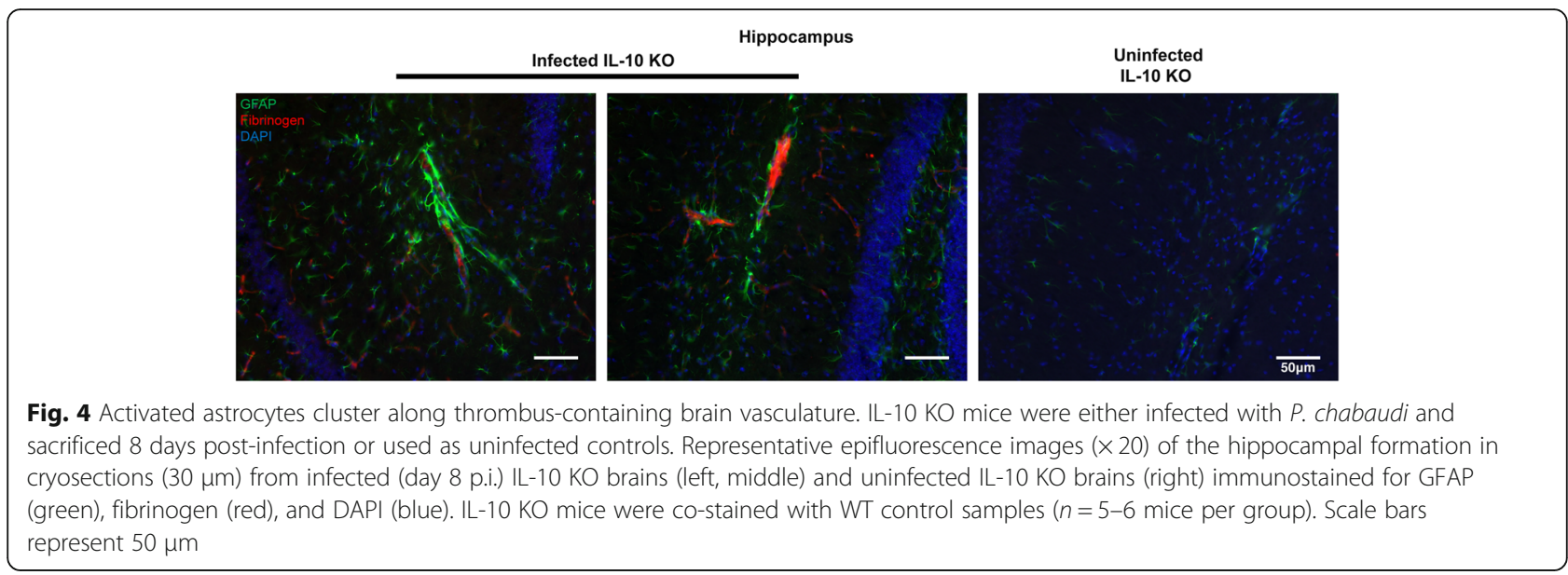

abbreviated SHIRPA screen before day 9 post-infection had a statistically significant chance of succumbing to infection, with an odds ratio of 23.7 (95\% CI 4.0-126.0, $\chi^{2}$ test), meaning they had almost 24 times more probability to succumb to disease. However, two out of 49 mice $(4.1 \%)$ that were predicted to die actually survived. In addition, due to the speed of progression from undetectable morbidity to mortality, some animals $(11 / 28,39 \%)$ will die naturally without ever exhibiting a low SHIRPA score.

To test the role of TNF in neuroimmunopathology and astrocyte activation in this infection, we treated IL-10 KO mice with neutralizing anti-TNF antibody or isotype control antibody for 5 days (days 5-9 p.i.) [14]. To monitor for fibrinogen accumulation and astrocyte activation, mice were sacrificed at day 8 p.i., at the onset of severe disease, and brain tissue was stained for confocal microscopy. We observed an increase in astrocyte activation and increased residual fibrinogen in isotype-treated IL-10 $\mathrm{KO}$ animals (Fig. 5a), but neither of these changes were observed in the IL-10 KO group treated with neutralizing anti-TNF antibodies (Fig. 5b), similar to isotype-treated WT mice (Fig. 5c). These changes were significant, with a complete reduction in fibrinogen accumulation (Fig. 5d) and astrocyte activation (Fig. 5e). Furthermore, animals were protected from behavioral symptoms during anti-TNF treatment (Fig. 5f). Behavioral symptoms declined after treatment stopped, but we did not observe any late mortality. As expected, excess production of fibrinogen in the liver was also reduced by anti-TNF treatment (Fig. 5g). As anti-TNF blocks many components of the acute phase reaction besides coagulation, we proceeded with more specific tests for the importance of coagulation to hyper-inflammatory experimental cerebral malaria.

\section{Anticoagulant treatment eliminates early mortality and} reduces glial cell activation in IL-10 KO mice with malaria To test the hypothesis that thrombi contribute to the fatal neurological phenotype of IL-10 KO mice infected with $P$. chabaudi, we treated infected IL-10 KO mice with the anticoagulant drug, enoxaparin sodium, a low-molecular weight heparin (LMWH), starting on day 4 post-infection through to the end of peak illness at day 12 post-infection, when all control animals had died. Mice were treated twice per day and monitored using the abbreviated SHIRPA screen. Blood smears were also collected on day 9 post-infection to monitor parasite burden. Strikingly, LMWH treatment of IL-10 KO mice rescued them from fatal neurologic disease before day 9 post-infection (Fig. 6a). However, LMWH-treated IL-10 KO mice were still susceptible to delayed mortality, as two out of four ENO-treated mice (50\%) died after day 9 post-infection. This may represent death from severe anemia that typically presents after the peak of $P$. chabaudi infection [65]. The differential mortality between treatment groups was not due to differences in parasitemia at the peak of infection on day 9 p.i., while behavioral scores were significantly improved with LMWH treatment (Fig. 6b). As a control to assure the quality of the treatment, we quantitated fibrinogen deposition in the brains of treated animals and confirmed that LMWH eliminated thrombi completely (Fig. 6c). Strikingly, we found that astrogliosis was significantly reduced by anticoagulant treatment, though not to the levels seen in uninfected animals (Fig. 6d). In conclusion, LMWH treatment decreased astrocyte activation and intravascular fibrin clotting, suggesting that thrombi in cerebral vasculature play a critical role in astrogliosis and lethal pathology from malaria without affecting parasitemia.

Microglia are important sentinels and potent amplifiers of inflammation within the CNS. In response to environmental cues and inflammatory stimuli, microglia become activated and undergo characteristic morphological changes. Therefore, we quantified both upregulation of Iba1, a marker of activation, and morphological changes characteristic of microglial activation in brain sections from either uninfected or P. chabaudi-infected 


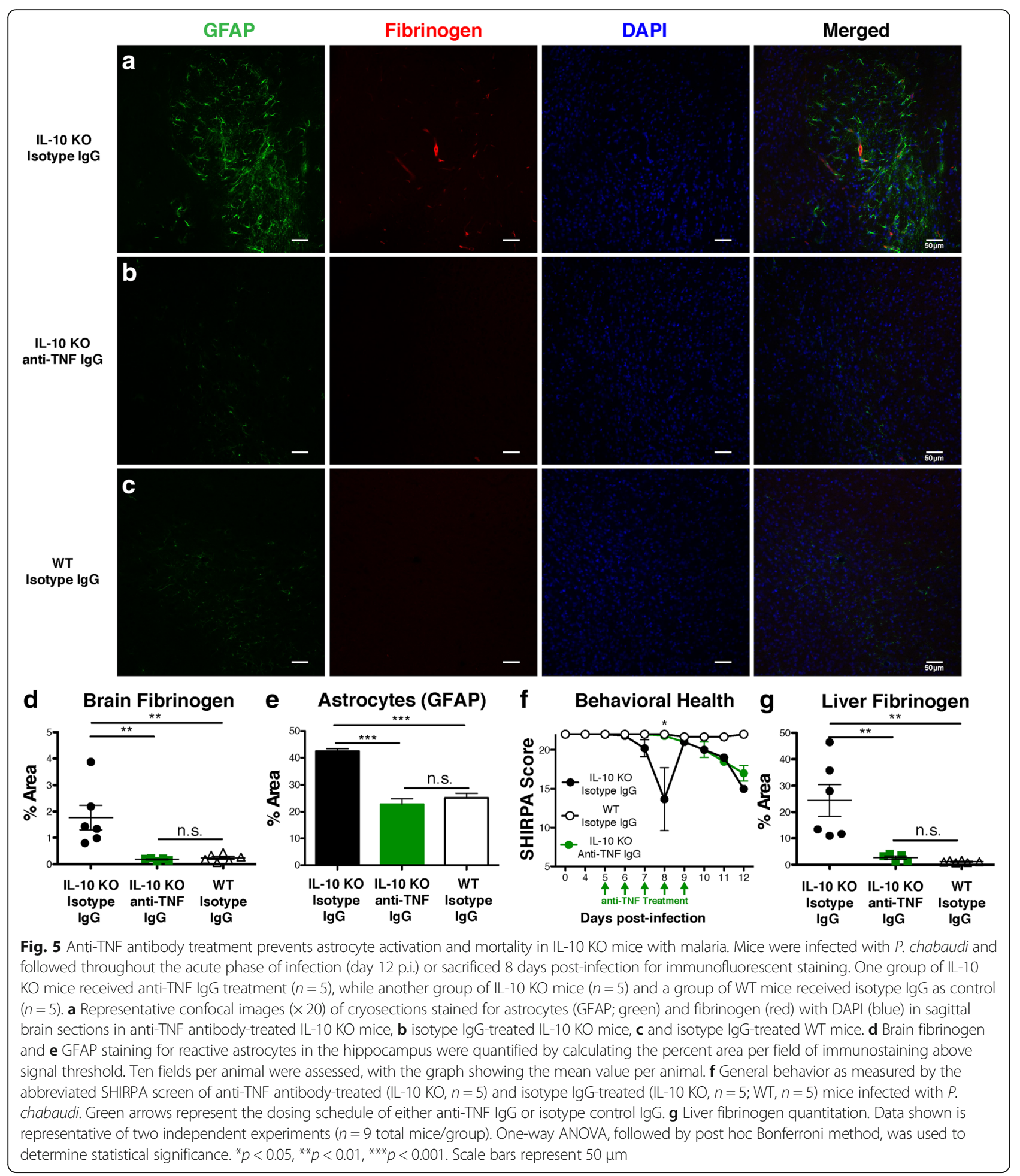

mice on day 8 p.i. (Fig. 7a). We observed dramatic changes in the microglia in the IL-10 KO compared to WT, and we observed further changes in the anticoagulant-treated animals. To interpret these changes, we quantitated the extent of microglial activation in these images based on morphology. We used four quantitative assessments: (1) total immunoreactive area (\% of total Iba1-positive pixels in a field); (2) average immunoreactive area per microglia; (3) transformation index, a measure of microglial ramification; and (4) area fraction of small processes, which is normalized to total immunoreactive area. The latter was done to 


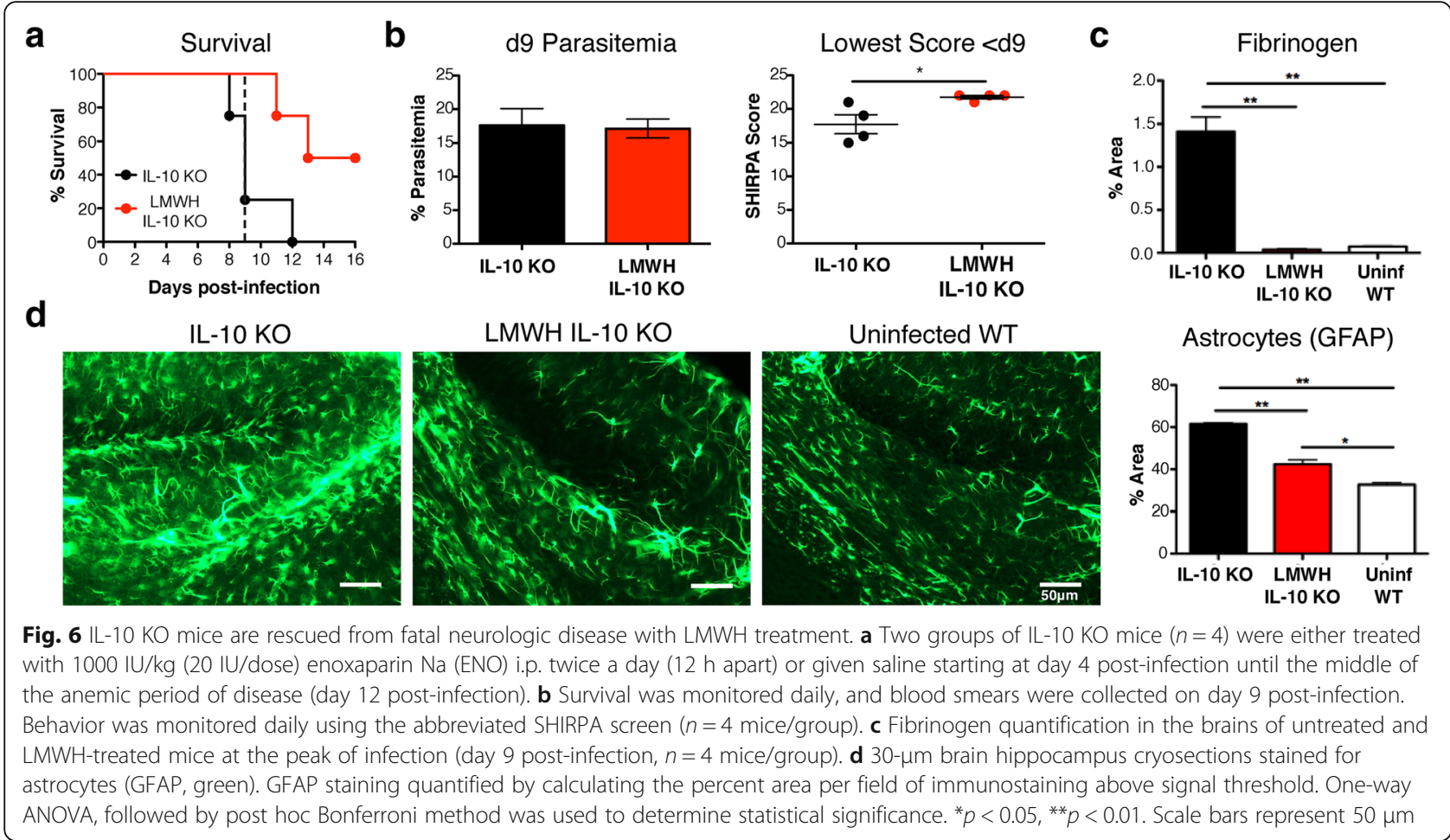

capture differences in small/fragmented processes, as small processes were not observed in the IL-10 KO group, while they were present in the LMWH group, although not as numerous as the WT group (Fig. 7b). The last graph, therefore, shows how much Iba1-reactive area each group has with respect to the area occupied by microglia soma, which was significantly lower in the untreated IL-10 $\mathrm{KO}$ group. We interpret this to mean that activated microglia retract their dendrites, which then appear thicker, as opposed to the thinner processes that cover more three-dimensional area in homeostasis. All of these measures suggest that microglial activation is reduced, but not back to homeostatic levels, by LMWH treatment, similar to what we found for astrogliosis above.

In order to determine the relative localization of activated microglia and cerebral vasculature, immunofluorescent staining was performed on microglia (Iba1) and $\mathrm{CD} 1^{+}$blood vessels (Fig. 7c). We observed increasing microglial polarity and thickening of dendrites in IL-10 $\mathrm{KO}$ animals, with decreased numbers of small processes in the microglia of untreated IL-10 KO mice. The localization of microglia near vessels in infected animals is clearly seen when viewed as a $3 D$ stack. Enumeration of the number of microglia that interacted with a blood vessel, defined as either body or process on the blood vessel, indicated $79 \%$ of glia interacted with a vessel in the KO group vs. $54 \%$ in the WT $(p<0.05)$, and while mean value for LMWH-treated IL-0 KO mice was 69\%, it was not statistically significant from either KO or WT.
The morphological changes in infected IL-10 KO mice show significant changes in microglial activation state, suggestive of increased intracranial inflammation. Interestingly, all features of activation show significant improvement towards homeostasis after clearance of thrombi following LMWH treatment. Therefore, these findings demonstrate a critical role of inflammation-driven coagulation in experimental cerebral malaria pathology.

\section{Discussion}

The presence of peripheral immune cells adherent within the vasculature in mouse models of CM and in brain vessels on autopsy of cerebral malaria patients [66] suggest that such cells play an important role in mediating neuropathology [67]. Current paradigms to explain CM pathogenesis support an important role for inflammation in the generation and amplification of neuropathology but do not explain the derivation of these cytokines in the brain. The derivation and contribution of cerebral thrombi to CM pathology is also poorly understood. The vascular findings in this study suggestive of pervasive (Fig. 1) and complete (Fig. 2) blockade of the vasculature by inflammation-induced thrombi are striking. These abnormalities have not been described in $P$. chabaudi infection before. Coagulation is clearly of major relevance for our understanding of pathological mechanisms in cerebral malaria [21, 58, 68]. Potentially pathogenic serum levels of both pro- and anticoagulation proteins have been documented in human CM [69, 


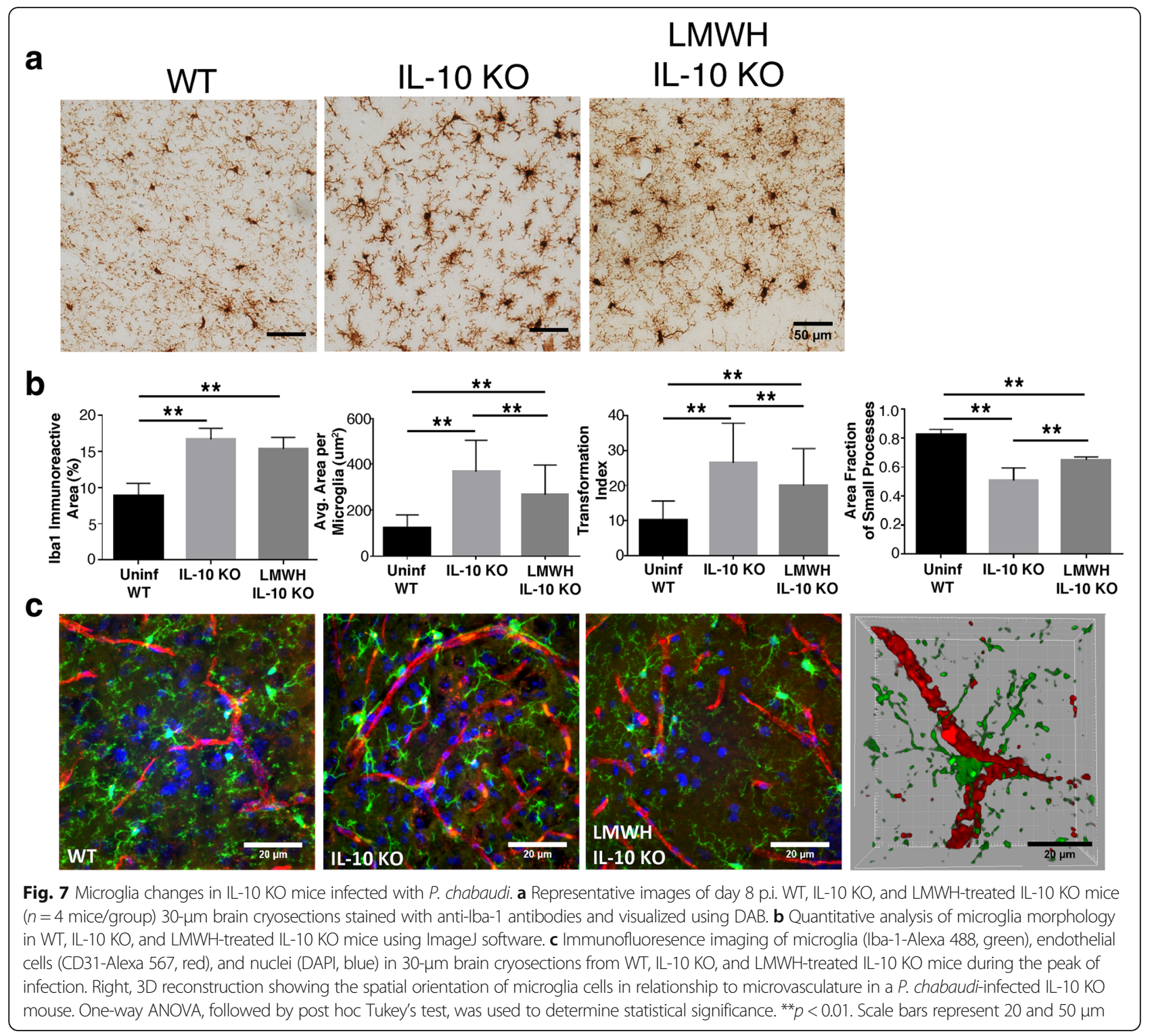

70]. Systemic inflammation has also recently been shown to contribute to intravascular clotting via mechanisms involving neutrophils and monocyte interaction with platelets in CM [71, 72], linking inflammation and clotting, which in turn promote sequestration. Recent studies also show that the anticoagulation endothelial protein $C$ receptor (EPCR) may bind the parasite and be downregulated, thus promoting clotting and suggesting a mechanism for the induction of coagulation by $P$. falciparum sequestration [45, 73]. Interestingly, studies point to the bi-directional amplification of the clotting cascade and inflammation suggesting an important intersection that is likely to be crucial to pathology in $\mathrm{CM}$ [58].

The data presented here confirm that inflammatory cells within the vasculature can drive both clot formation and activation of cells in the brain parenchyma in the absence of local parasite adhesion. Studies of Plasmodium berghei (ANKA) ( $\mathrm{PbA}$ ) infection have established the importance of the inflammatory response in the development of neurocognitive dysfunction [7476]. $\mathrm{PbA}$ infection shows pathogenic immune cell accumulation in cerebral blood vessels as a result of inflammatory TNF and IP-10 secretion [77, 78] and intercellular adhesion molecule-1 (ICAM-1) on the vascular endothelium [79]. PbA infection has also been shown to induce astrocyte activation and degeneration near sites of monocyte vascular adhesion [62, 80]. However, the signals leading to the breakdown of local astrocyte barrier function in malaria have not yet been defined. The activation of astrocytes is a feature of many neurological diseases, including cerebral malaria [81, 82]. 
Our results demonstrate a causal link between hyper-inflammation, hyper-coagulation, glial cell activation, and mortality (Figs. 3 and 4). Gliosis across multiple areas of the brain was observed in infected IL-10 $\mathrm{KO}$ mice, with astrocytes and microglia associating highly with the vasculature compared to the WT group-yet both microglial and astrocyte gliosis were significantly reduced upon LMWH treatment, indicating this direct link.

This is important because resolution of CM in African children and Asian adults can be resistant to anti-malarial drug treatment, suggesting that parasite alone does not cause the full cerebral malaria syndrome. Furthermore, it is not yet clear how parasite adhesion alone drives the neuropathology evident from patient symptoms [83]. However, because of the overlap of inflammation with parasite-dependent factors, determining the independent contributions of each presents an ongoing challenge to investigators. The impact of parasite adhesion to the vascular endothelium on coagulation, vascular integrity, and congestion has been shown in in vitro endothelial cultures and animal models of cerebral malaria $[19,43,67,84,85]$. Sequestration is seen in most fatal pediatric and adult CM cases $[20,21]$ and is used as a critical hallmark of disease. We chose to study the role of inflammatory cytokines in isolation from the potential contribution of sequestration using an inflammation-induced cerebral malaria model. The results confirm that inflammation can cause many of the pathological changes seen in CM, though not all.

In this study, we show that both the congestion phenotype associated with intravascular clotting and astrocyte activation can be reversed via neutralization of TNF (Fig. 5), or anticoagulant therapy (Fig. 6). Serum TNF concentration correlates with severity of human malaria [86]. However, TNF blockade has thus far proven ineffective in preventing death in childhood cerebral malaria [87, 88]. As different reagents displayed differential effects, the timing, dose, or precise antigenic specificity of treatments may yet be improved for adjuvant therapy. Strikingly, these data also show that fatal neurological disease in IL-10 KO mice is dependent on intravascular coagulation, as it can be prevented by LMWH treatment (Fig. 6). This demonstrates a central role for thrombi in driving the disease mortality and promoting neuropathology in $P$. chabaudi infection of IL-10 KO mice. As anti-TNF and anticoagulants have similar effects in this model, it is likely that cytokines and the coagulation cascade promote each other, as in other systems. Despite the WHO recommendation against the use of heparin since 1984, citing excessive bleeding [89], there are several clinical trials showing significant beneficial effects of anticoagulant usage on mortality and length of coma in human CM [49, 50, 90,
91]. Selection of treatments with relatively moderate anticoagulation activity is likely essential to achieving therapeutic goals while avoiding hemorrhagic complications. $\mathrm{LMWH}$, as the name implies, involves only the activity of the smaller heparin proteins, which act with higher specificity on factor Xa, exhibit less thrombin inhibition, and produce a more reliable therapeutic profile. Our studies show that LMWH treatment is protective within the context of hyper-inflammatory cerebral malaria and prevents intravascular thrombi formation in the brains of mice exhibiting behavioral dysfunction (Fig. 6). This is particularly important in that both astrocyte and microglial activation were dependent on this coagulation event to some degree (Figs. 6 and 7). Activation of microglia has been shown to be an important component of neuroinflammation and behavioral dysfunction associated with $\mathrm{PbA}$ infection [92-94]. Widespread microglial activation, not always restricted to areas of parasite sequestration, has also been identified in cases of human CM [95, 96]. However, these findings are novel in the context of $P$. chabaudi infection. Furthermore, the spatial relationship of intravascular coagulation with glial cell activation is also previously unknown in any malaria infection and should be examined in human CM autopsy samples.

Efforts to manipulate the inflammatory response and clotting cascade have provided mixed results in clinical trials to date [97-99], highlighting the importance of understanding the interactions between various arms of the host response within the pathogenesis of cerebral malaria. In summary, our experiments support the importance of intravascular coagulation and leukocytes producing inflammatory cytokines in malaria-induced cerebral pathology. The activation of surveilling microglia and vascular/neuronal-supportive astrocytes downstream of systemic inflammation could promote the generation of neuropathology secondary to malaria infection. Identification of both $\mathrm{T}$ cells and monocytes within fibrin clots suggests a new working model where inflammatory cells promote cerebral damage even from their localization within the cerebral vasculature. It is possible that leukocytes within the structure of intravascular thrombi serve to amplify pathological inflammatory cytokines leading to immunopathology in the brain. These data demonstrate the interaction of the anti-parasitic and hemostatic elements of host defense, promoting a new appreciation of the interplay between mechanisms important for development of fatal cerebral malaria.

\section{Conclusions}

Our study has identified intravascular thrombi within the cerebral vasculature during severe $P$. chabaudi infection and showed that they contribute to lethal immunopathology. Furthermore, vascular congestion with an 
accumulation of leukocytes is spatially associated with astrocyte and microglial activation in this model, with the former being driven by TNF. The most striking finding is that dissipation of these inflammatory foci within fibrin-rich thrombi by LMWH treatment leads to a significant decrease in early lethal pathology. These findings begin to define the parameters of inflammation in the brain during cerebral malaria, and the downstream pathology linked to hyper-inflammation. Previously, findings of cytokine gene linkage to $\mathrm{CM}$ were understood in terms of increasing parasite binding within the capillary bed. Our findings demonstrate that inflammatory cytokines contribute both pathogenic coagulation and activation of sentinel glia in the brain parenchyma, which are capable of causing neurological sequelae, even in the absence of localized sequestration, although to a lesser degree than more virulent parasites. These findings, therefore, contribute to the current understanding of the etiologies of cerebral pathology and neurovascular abnormalities in malaria infection. While the effectiveness and safety of this approach must be validated, the positive effect of anticoagulants could inform development of future adjunctive therapy for CM patients.

\section{Additional files}

Additional file 1: Figure S1. IL-10 KO mouse behavioral scores are predictive of outcome during $P$. chabaudi Infection. Left: representative experiment showing SHIRPA scores of infected male IL-10 KO mice grouped by eventual outcome (survived $=$ blue, $n=6$; died = black, $n=5$ ). Right: graph of the lowest abbreviated SHIRPA score in individual mice before day 9 post-infection with infected IL-10 KO mice grouped according to outcome. Showing concatenated data from multiple experiments $(n=48)$. Error bar represents SEM, ${ }^{* * *} p<0.001$, Wilcoxon signed rank test. (TIF $326 \mathrm{~kb}$ )

Additional file 2: Figure S2. IL-10 KO mice ammonia levels are not elevated above WT during P. chabaudi infection. WT and IL-10 KO mice were infected with $P$. chabaudi and monitored during the peak of infection. WT mice were sacrificed at the peak of infection (day 10 p.i.) and IL-10 KO mice upon severe morbidity as determined via SHIRPA score. Organ and plasma ammonia levels were measured using a colorimetric ammonia assay. (TIF $218 \mathrm{~kb}$ )

Additional file 3: Figure S3. $P$. chabaudi-infected IL-10 KO mice show astrocyte association with thrombi. Left, normalized astrocyte-thrombus association ratio. Right, representative confocal images of experimental groups stained for astrocytes (green) and fibrinogen (red). N $=3-5$ mice/ group. Error bar represents 30 m. (TIF $12464 \mathrm{~kb}$ )

\footnotetext{
Abbreviations

3D: Three-dimensional; BBB: Blood-brain-barrier; CM: Cerebral malaria; CNS: Central nervous system; CXCR3: C-X chemokine receptor 3; DIC: Disseminated intravascular coagulation; ECM: Experimental cerebral malaria; GFAP: Glial fibrillary acidic protein; i.p.: Intraperitoneal; ICAM1: Intracellular adhesion molecule-1; IFN- - : Interferon gamma; IHC: Immunohistochemistry; IL-10 KO: IL-10-deficient; iRBCs: Infected red blood cells; MHC-II: Major histocompatibility complex class II; PbA: Plasmodium berghei (ANKA); SHIRPA: SmithKline Beecham, Harwell, Imperial College, Royal London Hospital Phenotype Assessment; TNF: Tumor necrosis factor; WT: Wild-type, C57BI/6J
}

\section{Acknowledgements}

We would like to acknowledge Andrew S. Mendiola for suggesting the fibrinogen stain and for the immunofluorescence protocols from the Cardona laboratory. We appreciate Ping Wu, Tiffany Dunn, Yongquan Jiang, Paula Villarreal, and the Biomedical Imaging Network at UTMB for the technical assistance in the sample prep and confocal microscopy. We appreciate the feedback from the UTMB Joint Immunology Lab Meeting and the Neuro-Infectious Diseases working group organized by the UTMB Institute for Human Infection and Immunity, particularly Kathryn Cunningham and Kelly Dineley. We are also indebted to Linsey Yeager for the critical review of the manuscript. We are grateful for the excellent animal care by the UTMB Animal Resource Center and the training from the Rodent In Vivo Assessment Core.

\section{Funding}

Funding for these studies was from the UTMB Institute for Human Infections and Immunity (IHII) and the John S. Dunn Foundation (RS, KDW), McLaughlin Endowment Predoctoral Grant and Jeane B. Kempner Award (KDW), and $\mathrm{NIH}$ (R01Al363327 (RS), R01NS078501 (AEC), and T32Al363327 (KDW)). This study was also supported by a grant from the University of Texas System Neuroscience and Neurotechnology Research Institute (RS, GV, \#363327). The funders had no role in the study design, data collection and interpretation, or the decision to submit the work for publication.

\section{Availability of data and materials}

All data generated or analyzed during this study are included in this published article and its supplementary information files.

\section{Authors' contributions}

Epifluorescent and confocal imaging studies were designed by KDW, GV, RS, conducted by KDW, with assistance from LFO and ODS, and analyzed by KDW, GV, and RS. Two-photon imaging studies were designed by GV and RS, conducted by LFO and ODS, and analyzed by LFO, ODS, and GV. Fibrinogen and microglia imaging studies were designed by KDW, RS, and AEC, conducted by KDW and SMC, and analyzed by KDW, RS, GV, LFO, and RP. Adoptive transfer, antibody treatment, and animal behavior studies were designed by KDW and RS, conducted by KDW, and analyzed by KDW and RS. Tissue ammonia quantitation were performed and analyzed by VHC and ODS. Statistical analyses and figures were generated by KDW, LFO, ODS, VHC, and PHK. KDW and RS drafted the manuscript, with essential input from GV, LFO, ODS, and AEC. All authors read and approved the final manuscript.

\section{Ethics approval}

Animals were cared for according to the Guide for the Care and Use of Laboratory Animals under the Institutional Animal Care and Use Committeeapproved protocol \#1006031. UTMB Animal Resource Center facilities operate in compliance with the USDA Animal Welfare Act, the Guide for the Care and Use of Laboratory Animals, under OLAW accreditation, and IACUC-approved protocols.

\section{Competing interests}

The authors declare that they have no competing interests.

\section{Publisher's Note}

Springer Nature remains neutral with regard to jurisdictional claims in published maps and institutional affiliations.

\footnotetext{
Author details

${ }^{1}$ Department of Microbiology and Immunology, University of Texas Medical Branch, 301 University Boulevard, Galveston, TX 77555, USA. ${ }^{2}$ Center for Biomedical Engineering, University of Texas Medical Branch, 301 University Boulevard, Galveston, TX 77555, USA. ${ }^{3}$ Department of Biology, One UTSA Circle, University of Texas at San Antonio, San Antonio, TX 78249, USA. ${ }^{4}$ Department of Neuroscience and Cell Biology, University of Texas Medical Branch, 301 University Boulevard, Galveston, TX 77555, USA. ${ }^{5}$ Department of Internal Medicine, Division of Infectious Diseases, University of Texas Medical Branch, 301 University Boulevard, Galveston, TX 77555-0435, USA. ${ }^{6}$ Institute for Human Infections and Immunity, University of Texas Medical Branch, 301 University Boulevard, Galveston, TX 77555, USA.
} 


\section{Received: 14 February 2018 Accepted: 17 May 2018}

Published online: 04 June 2018

\section{References}

1. World Malaria Report 2016. Geneva: World Health Organization; 2016. http:// www.who.int/malaria/publications/world-malaria-report-2016/report/en/. Accessed 13 March 2018

2. Seydel KB, Kampondeni SD, Valim C, Potchen MJ, Milner DA, Muwalo FW, Birbeck GL, Bradley WG, Fox LL, Glover SJ, et al. Brain swelling and death in children with cerebral malaria. N Engl J Med. 2015;372:1126-37.

3. Idro R, Jenkins NE, Newton CR. Pathogenesis, clinical features, and neurological outcome of cerebral malaria. Lancet Neurol. 2005;4:827-40.

4. Idro R, Kakooza-Mwesige A, Balyejjussa S, Mirembe G, Mugasha C, Tugumisirize J, Byarugaba J. Severe neurological sequelae and behaviour problems after cerebral malaria in Ugandan children. BMC Res Notes. 2010:3:104.

5. Armah HB, Wilson NO, Sarfo BY, Powell MD, Bond VC, Anderson W, Adjei AA, Gyasi RK, Tettey Y, Wiredu EK, et al. Cerebrospinal fluid and serum biomarkers of cerebral malaria mortality in Ghanaian children. Malar J. 2007;6:147.

6. McGuire W, Hill AV, Allsopp CE, Greenwood BM, Kwiatkowski D. Variation in the TNF-alpha promoter region associated with susceptibility to cerebral malaria. Nature. 1994;371:508-10

7. Ouma C, Davenport GC, Were T, Otieno MF, Hittner JB, Vulule JM, Martinson J, Ong'echa JM, Ferrell RE, Perkins DJ. Haplotypes of IL-10 promoter variants are associated with susceptibility to severe malarial anemia and functional changes in IL-10 production. Hum Genet. 2008;124:515-24.

8. Burt RA, Baldwin TM, Marshall VM, Foote SJ. Temporal expression of an H2-linked locus in host response to mouse malaria. Immunogenetics. 1999;50:278-85.

9. Knight JC, Udalova I, Hill AVS, Greenwood BM, Peshu N, Marsh K, Kwiatkowski D. A polymorphism that affects OCT-1 binding to the TNF promoter region is associated with severe malaria. Nat Genet. 1999;22:145.

10. Fortin A, Stevenson MM, Gros P. Complex genetic control of susceptibility to malaria in mice. Genes Immun. 2002;3:177-86.

11. Amante FH, Haque A, Stanley AC, Rivera Fde L, Randall LM, Wilson YA, Yeo G, Pieper C, Crabb BS, de Koning-Ward TF, et al. Immune-mediated mechanisms of parasite tissue sequestration during experimental cerebral malaria. J Immunol. 2010;185:3632-42.

12. Chakravorty SJ, Carret C, Nash GB, Ivens A, Szestak T, Craig AG. Altered phenotype and gene transcription in endothelial cells, induced by Plasmodium falciparum-infected red blood cells: pathogenic or protective? Int J Parasitol. 2007;37:975-87.

13. Palomo J, Reverchon F, Piotet J, Besnard AG, Couturier-Maillard A, Maillet I, Tefit M, Erard F, Mazier D, Ryffel B, Quesniaux VF. Critical role of IL-33 receptor ST2 in experimental cerebral malaria development. Eur J Immunol. 2015:45:1354-65

14. Li C, Sanni LA, Omer F, Riley E, Langhorne J. Pathology of Plasmodium chabaudi chabaudi infection and mortality in interleukin-10-deficient mice are ameliorated by anti-tumor necrosis factor alpha and exacerbated by antitransforming growth factor beta antibodies. Infect Immun. 2003;71:4850-6.

15. Sanni LA, Jarra W, Li C, Langhorne J. Cerebral edema and cerebral hemorrhages in interleukin-10-deficient mice infected with Plasmodium chabaudi. Infect Immun. 2004;72:3054-8.

16. Wilson KD, Stutz SJ, Ochoa LF, Valbuena GA, Cravens PD, Dineley KT, Vargas $\mathrm{G}$, Stephens R. Behavioural and neurological symptoms accompanied by cellular neuroinflammation in IL-10-deficient mice infected with Plasmodium chabaudi. Malar J. 2016:15:428.

17. Mota MM, Jarra W, Hirst E, Patnaik PK, Holder AA. Plasmodium chabaudiinfected erythrocytes adhere to CD36 and bind to microvascular endothelial cells in an organ-specific way. Infect Immun. 2000;68:4135-44.

18. Brugat T, Cunningham D, Sodenkamp J, Coomes S, Wilson M, Spence PJ, Jarra W, Thompson J, Scudamore C, Langhorne J. Sequestration and histopathology in Plasmodium chabaudi malaria are influenced by the immune response in an organ-specific manner. Cell Microbiol. 2014;16:687-700.

19. Cunningham DA, Lin JW, Brugat T, Jarra W, Tumwine I, Kushinga G, Ramesar J, Franke-Fayard B, Langhorne J. ICAM-1 is a key receptor mediating cytoadherence and pathology in the Plasmodium chabaudi malaria model. Malar J. 2017:16:185

20. Dorovini-Zis K, Schmidt K, Huynh H, Fu W, Whitten RO, Milner D, Kamiza S, Molyneux M, Taylor TE. The neuropathology of fatal cerebral malaria in Malawian children. Am J Pathol. 2011;178:2146-58.

21. Ponsford MJ, Medana IM, Prapansilp P, Hien TT, Lee SJ, Dondorp AM, Esiri MM, Day NP, White NJ, Turner GD. Sequestration and microvascular congestion are associated with coma in human cerebral malaria. J Infect Dis. 2012;205:663-71.

22. Jensen AT, Magistrado P, Sharp S, Joergensen L, Lavstsen T, Chiucchiuini A, Salanti A, Vestergaard LS, Lusingu JP, Hermsen R, et al. Plasmodium falciparum associated with severe childhood malaria preferentially expresses PfEMP1 encoded by group A var genes. J Exp Med. 2004;199:1179-90.

23. Bernabeu M, Danziger SA, Avril M, Vaz M, Babar PH, Brazier AJ, Herricks T, Maki JN, Pereira L, Mascarenhas A, et al. Severe adult malaria is associated with specific PfEMP1 adhesion types and high parasite biomass. Proc Natl Acad Sci U S A. 2016;113:E3270-9.

24. Lavstsen T, Turner L, Saguti F, Magistrado P, Rask TS, Jespersen JS, Wang CW, Berger SS, Baraka V, Marquard AM, et al. Plasmodium falciparum erythrocyte membrane protein 1 domain cassettes 8 and 13 are associated with severe malaria in children. Proc Natl Acad Sci U S A. 2012;109:E1791-800

25. Avril M, Tripathi AK, Brazier AJ, Andisi C, Janes JH, Soma VL, Sullivan DJ Jr, Bull PC, Stins MF, Smith JD. A restricted subset of var genes mediates adherence of Plasmodium falciparum-infected erythrocytes to brain endothelial cells. Proc Natl Acad Sci U S A. 2012;109:E1782-90.

26. Grau GE, Piguet PF, Vassalli P, Lambert PH. Tumor-necrosis factor and other cytokines in cerebral malaria: experimental and clinical data. Immunol Rev. 1989;112:49-70.

27. Kwiatkowski DP, Luoni G. Host genetic factors in resistance and susceptibility to malaria. Parassitologia. 2006;48:450-67.

28. May J, Lell B, Luty AJ, Meyer CG, Kremsner PG. Plasma interleukin-10: tumor necrosis factor (TNF)-alpha ratio is associated with TNF promoter variants and predicts malarial complications. J Infect Dis. 2000;182:1570-3.

29. Ho M, Schollaardt T, Snape S, Looareesuwan S, Suntharasamai P, White NJ. Endogenous interleukin-10 modulates proinflammatory response in Plasmodium falciparum malaria. J Infect Dis. 1998;178:520-5.

30. Freitas do Rosario AP, Langhorne J. T cell-derived IL-10 and its impact on the regulation of host responses during malaria. Int J Parasitol. 2012;42:549-55.

31. Li C, Corraliza I, Langhorne J. A defect in interleukin-10 leads to enhanced malarial disease in Plasmodium chabaudi chabaudi infection in mice. Infect Immun. 1999:67:4435-42.

32. Freitas do Rosario AP, Lamb T, Spence P, Stephens R, Lang A, Roers A Muller W, O'Garra A, Langhorne J. IL-27 promotes IL-10 production by effector Th1 CD4+ T cells: a critical mechanism for protection from severe immunopathology during malaria infection. J Immunol. 2012;188:1178-90.

33. Couper KN, Blount DG, Wilson MS, Hafalla JC, Belkaid Y, Kamanaka M, Flavell RA, de Souza JB, Riley EM. IL-10 from CD4CD25Foxp3CD127 adaptive regulatory $T$ cells modulates parasite clearance and pathology during malaria infection. PLoS Pathog. 2008;4:e1000004.

34. Turner GD, Morrison H, Jones M, Davis TM, Looareesuwan S, Buley ID, Gatter KC, Newbold Cl, Pukritayakamee S, Nagachinta B, et al. An immunohistochemical study of the pathology of fatal malaria. Evidence for widespread endothelial activation and a potential role for intercellular adhesion molecule-1 in cerebral sequestration. Am J Pathol. 1994:145:1057-69.

35. MacPherson GG, Warrell MJ, White NJ, Looareesuwan S, Warrell DA. Human cerebral malaria. A quantitative ultrastructural analysis of parasitized erythrocyte sequestration. Am J Pathol. 1985;119:385-401.

36. Turner G. Cerebral malaria. Brain Pathol. 1997:7:569-82.

37. Spitz S. The pathology of acute falciparum malaria. Mil Surg. 1946;99:555-72

38. Berendt AR, Tumer GDH, Newbold Cl. Cerebral malaria: the sequestration hypothesis. Parasitol Today. 1994;10:412-4.

39. Pongponratn E, Turner GD, Day NP, Phu NH, Simpson JA, Stepniewska K, Mai NT, Viriyavejakul P, Looareesuwan S, Hien TT, et al. An ultrastructural study of the brain in fatal Plasmodium falciparum malaria. Am J Trop Med Hyg. 2003;69:345-59.

40. White NJ, Turner GD, Medana IM, Dondorp AM, Day NP. The murine cerebral malaria phenomenon. Trends Parasitol. 2010;26:11-5.

41. Lewallen S, Bakker H, Taylor TE, Wills BA, Courtright P, Molyneux ME. Retinal findings predictive of outcome in cerebral malaria. Trans R Soc Trop Med Hyg. 1996;90:144-6.

42. Patnaik JK, Das BS, Mishra SK, Mohanty S, Satpathy SK, Mohanty D. Vascular clogging, mononuclear cell margination, and enhanced vascular permeability in the pathogenesis of human cerebral malaria. Am J Trop Med Hyg. 1994;51:642-7.

43. Franke-Fayard B, Janse CJ, Cunha-Rodrigues $M$, Ramesar J, Buscher P, Que I, Lowik C, Voshol PJ, den Boer MA, van Duinen SG, et al. Murine malaria parasite sequestration: CD36 is the major receptor, but cerebral pathology is unlinked to sequestration. Proc Natl Acad Sci U S A. 2005;102:11468-73. 
44. Bridges DJ, Bunn J, van Mourik JA, Grau G, Preston RJ, Molyneux M, Combes V, O'Donnell JS, de Laat B, Craig A. Rapid activation of endothelial cells enables Plasmodium falciparum adhesion to platelet-decorated von Willebrand factor strings. Blood. 2010;115:1472-4.

45. Moxon CA, Wassmer SC, Milner DA, Jr., Chisala NV, Taylor TE, Seydel KB, Molyneux ME, Faragher B, Esmon CT, Downey C, et al: Loss of endothelial protein $C$ receptors links coagulation and inflammation to parasite sequestration in cerebral malaria in African children. Blood 2013, 122:842-851.

46. O'Regan N, Gegenbauer K, O'Sullivan JM, Maleki S, Brophy TM, Dalton N, Chion A, Fallon PG, Grau GE, Budde U, et al. A novel role for von Willebrand factor in the pathogenesis of experimental cerebral malaria. Blood. 2016;127:1192-201.

47. Sun G, Chang WL, Li J, Berney SM, Kimpel D, van der Heyde HC. Inhibition of platelet adherence to brain microvasculature protects against severe Plasmodium berghei malaria. Infect Immun. 2003;71:6553-61.

48. Moxon CA, Chisala NV, Mzikamanda R, MacCormick I, Harding S, Downey C, Molyneux M, Seydel KB, Taylor TE, Heyderman RS, Toh CH. Laboratory evidence of disseminated intravascular coagulation is associated with a fatal outcome in children with cerebral malaria despite an absence of clinically evident thrombosis or bleeding. J Thromb Haemost. 2015;13:1653-64.

49. Rampengan $\mathrm{TH}$. Cerebral malaria in children. Comparative study between heparin, dexamethasone and placebo. Paediatrica Indonesiana. 1991;31: 59-66.

50. Munir M, Tjandra H, Rampengan TH, Mustadjab I, Wulur FH. Heparin in the treatment of cerebral malaria. Paediatr Indones. 1980;20:47-50.

51. Reid HA, Sucharit P. Ancrod, heparin, and -aminocaproic acid in simian Knowlesi malaria. Lancet. 1972;2:1110-2.

52. Stone WJ, Hanchett JE, Knepshield JH. Acute renal insufficiency due to falciparum malaria. Review of 42 cases. Arch Intern Med. 1972;129:620-8.

53. Grau GE, Craig AG. Cerebral malaria pathogenesis: revisiting parasite and host contributions. Future Microbiol. 2012;7:291-302.

54. Rogers DC, Fisher EM, Brown SD, Peters J, Hunter AJ, Martin JE. Behavioral and functional analysis of mouse phenotype: SHIRPA, a proposed protocol for comprehensive phenotype assessment. Mamm Genome. 1997;8:711-3.

55. Stephens R, Langhorne J. Effector memory Th1 CD4 T cells are maintained in a mouse model of chronic malaria. PLoS Pathog. 2010;6:e1001208.

56. Chung K, Wallace J, Kim S-Y, Kalyanasundaram S, Andalman AS, Davidson TJ, Mirzabekov JJ, Zalocusky KA, Mattis J, Denisin AK, et al. Structural and molecular interrogation of intact biological systems. Nature. 2013;497:332-7.

57. Bertini R, Bianchi M, Villa P, Ghezzi P. Depression of liver drug metabolism and increase in plasma fibrinogen by interleukin 1 and tumor necrosis factor: a comparison with lymphotoxin and interferon. Int J Immunopharmacol. 1988;10:525-30.

58. Francischetti IM, Seydel KB, Monteiro RQ. Blood coagulation, inflammation, and malaria. Microcirculation. 2008;15:81-107.

59. Blombäck B, Hessel B, Hogg D, Therkildsen L. A two-step fibrinogen—fibrin transition in blood coagulation. Nature. 1978;275:501-5.

60. Raut S, McEvoy F, Gaffney PJ. Development of an ELISA for the quantification of fibrin in canine tumours. Thromb Res. 1999;96:11-7.

61. Clemmensen I. Three new E-antigenic fibrinogen fractions found in a commercial plasmin preparation. Science Tools LKB Instr J. 1973;20:7-8.

62. Medana IM, Chaudhri G, Chan-Ling T, Hunt NH. Central nervous system in cerebral malaria: 'innocent bystander' or active participant in the induction of immunopathology? Immunol Cell Biol. 2001;79:101-20.

63. Ridet JL, Privat A, Malhotra SK, Gage FH. Reactive astrocytes: cellular and molecular cues to biological function. Trends Neurosci. 1997;20:570-7.

64. Haussinger D, Schliess F. Pathogenetic mechanisms of hepatic encephalopathy. Gut. 2008:57:1156-65.

65. Yap GS, Stevenson MM. Blood transfusion alters the course and outcome of Plasmodium chabaudi AS infection in mice. Infect Immun. 1994;62:3761-5.

66. Brown $H$, Hien $T$, Day $N$, Mai NT, Chuong LV, Chau TT, Loc PP, Phu $\mathrm{NH}$, Bethell D, Farrar J, et al. Evidence of blood-brain barrier dysfunction in human cerebral malaria. Neuropathol Appl Neurobiol. 1999;25:331-40

67. Nacer A, Movila A, Baer K, Mikolajczak SA, Kappe SH, Frevert U. Neuroimmunological blood brain barrier opening in experimental cerebral malaria. PLoS Pathog. 2012;8:e1002982.

68. Milner DA, Whitten RO, Kamiza S, Carr R, Liomba G, Dzamalala C, Seydel KB, Molyneux ME, Taylor TE. The systemic pathology of cerebral malaria in African children. Front Cell Infect Microbiol. 2014;4:104.

69. Borochovitz D, Crosley AL, Metz J. Disseminated intravascular coagulation with fatal haemorrhage in cerebral malaria. Br Med J. 1970;2:710.
70. Reid HA, Nkrumah FK. Fibrin-degradation products in cerebral malaria Lancet. 1972;1:218-21.

71. Feintuch CM, Saidi A, Seydel K, Chen G, Goldman-Yassen A, Mita-Mendoza NK, Kim RS, Frenette PS, Taylor T, Daily JP. Activated neutrophils are associated with pediatric cerebral malaria vasculopathy in Malawian children. MBio. 2016;7:e01300-15.

72. Hochman SE, Madaline TF, Wassmer SC, Mbale E, Choi N, Seydel KB, Whitten $\mathrm{RO}$, Varughese J, Grau GE, Kamiza S, et al. Fatal pediatric cerebral malaria is associated with intravascular monocytes and platelets that are increased with HIV coinfection. MBio. 2015;6:e01390-15.

73. Sampath S, Brazier AJ, Avril M, Bernabeu M, Vigdorovich V, Mascarenhas A Gomes E, Sather DN, Esmon CT, Smith JD. Plasmodium falciparum adhesion domains linked to severe malaria differ in blockade of endothelial protein C receptor. Cell Microbiol. 2015;17:1868-82.

74. Desruisseaux MS, Gulinello M, Smith DN, Lee SC, Tsuji M, Weiss LM, Spray DC, Tanowitz HB. Cognitive dysfunction in mice infected with Plasmodium berghei strain ANKA. J Infect Dis. 2008;197:1621-7.

75. Lackner P, Beer R, Heussler V, Goebel G, Rudzki D, Helbok R, Tannich E, Schmutzhard E. Behavioural and histopathological alterations in mice with cerebral malaria. Neuropathol Appl Neurobiol. 2006;32:177-88.

76. Lacerda-Queiroz N, Rodrigues DH, Vilela MC, Miranda AS, Amaral DC, Camargos ER, Carvalho LJ, Howe CL, Teixeira MM, Teixeira AL. Inflammatory changes in the central nervous system are associated with behavioral impairment in Plasmodium berghei (strain ANKA)-infected mice. Exp Parasitol. 2010;125:271-8.

77. Nie CQ, Bernard NJ, Norman MU, Amante FH, Lundie RJ, Crabb BS, Heath WR, Engwerda CR, Hickey MJ, Schofield L, Hansen DS. IP-10-mediated T cell homing promotes cerebral inflammation over splenic immunity to malaria infection. PLoS Pathog. 2009;5:e1000369.

78. Campanella GS, Tager AM, El Khoury JK, Thomas SY, Abrazinski TA, Manice LA, Colvin RA, Luster AD. Chemokine receptor CXCR3 and its ligands CXCL9 and $\mathrm{CXCL} 10$ are required for the development of murine cerebral malaria. Proc Natl Acad Sci U S A. 2008;105:4814-9.

79. Rudin W, Eugster HP, Bordmann G, Bonato J, Müller M, Yamage M, Ryffel B. Resistance to cerebral malaria in tumor necrosis factor-alpha/beta-deficient mice is associated with a reduction of intercellular adhesion molecule- 1 upregulation and T helper type 1 response. Am J Pathol. 1997;150:257-66.

80. Ampawong S, Chaisri U, Viriyavejakul P, Nontprasert A, Grau GE, Pongponratn E. Electron microscopic features of brain edema in rodent cerebral malaria in relation to glial fibrillary acidic protein expression. Int J Clin Exp Pathol. 2014;7:2056-67.

81. Ma N, Madigan MC, Chan-Ling T, Hunt NH. Compromised blood-nerve barrier, astrogliosis, and myelin disruption in optic nerves during fatal murine cerebral malaria. Glia. 1997;19:135-51.

82. Medana IM, Turner GDH. Human cerebral malaria and the blood-brain barrier. Int J Parasitol. 2006;36:555-68.

83. O'Sullivan JM, Preston RJ, O'Regan N, O'Donnell JS. Emerging roles for hemostatic dysfunction in malaria pathogenesis. Blood. 2016;127:2281-8.

84. Hearn J, Rayment N, Landon DN, Katz DR, de Souza JB. Immunopathology of cerebral malaria: morphological evidence of parasite sequestration in murine brain microvasculature. Infect Immun. 2000;68:5364-76.

85. Franke-Fayard B, Fonager J, Braks A, Khan SM, Janse CJ. Sequestration and tissue accumulation of human malaria parasites: can we learn anything from rodent models of malaria? PLoS Pathog. 2010;6:e1001032.

86. Kwiatkowski D, Sambou I, Twumasi P, Greenwood BM, Hill AVS, Manogue KR, Cerami A, Castracane J, Brewster DR. TNF concentration in fatal cerebral, non-fatal cerebral, and uncomplicated Plasmodium falciparum malaria. Lancet. 1990:336:1201-4.

87. van Hensbroek MB, Palmer A, Onyiorah E, Schneider G, Jaffar S, Dolan G, Memming $\mathrm{H}$, Frenkel J, Enwere $\mathrm{G}$, Bennett $\mathrm{S}$, et al. The effect of a monoclonal antibody to tumor necrosis factor on survival from childhood cerebral malaria. J Infect Dis. 1996;174:1091-7.

88. Kwiatkowski D, Molyneux ME, Stephens S, Curtis N, Klein N, Pointaire P, Smit M, Allan R, Brewster DR, Grau GE, et al. Anti-TNF therapy inhibits fever in cerebral malaria. Q J Med. 1993;86:91-8.

89. Severe and complicated malaria. World Health Organization Malaria Action Programme. Trans R Soc Trop Med Hyg. 1986;80 Suppl:3-50.

90. Havlik I, Looareesuwan S, Vannaphan S, Wilairatana P, Krudsood S, Thuma PE, Kozbor D, Watanabe N, Kaneko Y. Curdlan sulphate in human severe/ cerebral Plasmodium falciparum malaria. Trans R Soc Trop Med Hyg. 2005: 99:333-40. 
91. Jaroonvesama N. Intravascular coagulation in falciparum malaria. Lancet. 1972;1:221-3.

92. Sarkar S, Keswani T, Sengupta A, Mitra S, Bhattacharyya A. Differential modulation of glial cell mediated neuroinflammation in Plasmodium berghei ANKA infection by TGF beta and IL 6. Cytokine. 2017;99:249-59.

93. Reverchon F, Mortaud S, Sivoyon M, Maillet I, Laugeray A, Palomo J, Montecot C, Herzine A, Meme S, Meme W, et al. IL-33 receptor ST2 regulates the cognitive impairments associated with experimental cerebral malaria. PLoS Pathog. 2017;13:e1006322.

94. Capuccini B, Lin J, Talavera-Lopez C, Khan SM, Sodenkamp J, Spaccapelo R, Langhorne J. Transcriptomic profiling of microglia reveals signatures of cell activation and immune response, during experimental cerebral malaria. Sci Rep. 2016;6:39258.

95. Schluesener HJ, Kremsner PG, Meyermann R. Widespread expression of MRP8 and MRP14 in human cerebral malaria by microglial cells. Acta Neuropathol. 1998;96:575-80.

96. Deininger MH, Kremsner PG, Meyermann R, Schluesener H. Macrophages/ microglial cells in patients with cerebral malaria. Eur Cytokine Netw. 2002; 13:173-85.

97. Warrell DA, Looareesuwan S, Warrell MJ, Kasemsarn P, Intaraprasert R, Bunnag D, Harinasuta T. Dexamethasone proves deleterious in cerebral malaria. N Engl J Med. 1982;306:313-9.

98. Di Perri G, Di Perri HG, Monteiro GB, Bonora S, Hennig C, Cassatella M, Micciolo R, Vento S, Dusi S, Bassetti D, Concia E. Pentoxifylline as a supportive agent in the treatment of cerebral malaria in children. J Infect Dis. 1995;171:1317-22.

99. Hemmer CJ, Kern P, Holst FGE, Nawroth PP, Dietrich M. Neither heparin nor acetylsalicylic acid influence the clinical course in human Plasmodium falciparum malaria: a prospective randomized study. Am J Trop Med Hyg. 1991:45:608-12.

Ready to submit your research? Choose BMC and benefit from:

- fast, convenient online submission

- thorough peer review by experienced researchers in your field

- rapid publication on acceptance

- support for research data, including large and complex data types

- gold Open Access which fosters wider collaboration and increased citations

- maximum visibility for your research: over $100 \mathrm{M}$ website views per year

At BMC, research is always in progress.

Learn more biomedcentral.com/submissions 